\title{
Defects in memory B-cell and plasma cell subsets expressing different immunoglobulin-subclasses in patients with CVID and immunoglobulin subclass deficiencies
}

Elena Blanco, $\mathrm{PhD},{ }^{\mathrm{a}, \mathrm{b} *}$ Martín Pérez-Andrés, $\mathrm{PhD},{ }^{\mathrm{a}, \mathrm{b} *}$ Sonia Arriba-Méndez, $\mathrm{MD}, \mathrm{PhD}^{\mathrm{c}}$ Cristina Serrano, $\mathrm{MD},{ }^{\mathrm{d}}$ Ignacio Criado, PhD, ${ }^{\text {a,b }}$ Lucía Del Pino-Molina, PhD, ${ }^{\text {e }}$ Susana Silva, MD, PhD, ${ }^{f}$ Ignacio Madruga, MD, ${ }^{\mathrm{g}}$ Marina Bakardjieva, MSc, ${ }^{\mathrm{h}}$ Catarina Martins, PhD, ${ }^{\mathrm{i}}$ Ana Serra-Caetano, MSc, ${ }^{\mathrm{f}}$ Alfonso Romero, MD, Teresa Contreras-Sanfeliciano, MD, ${ }^{\mathrm{k}}$ Carolien Bonroy, PhD,' Francisco Sala, MD, ${ }^{\mathrm{m}}$ Alejandro Martín, MD, PhD, ${ }^{\mathrm{n}, \mathrm{o}}$ José María Bastida, MD, PhD, ${ }^{\mathrm{n}, \mathrm{o}}$ Félix Lorente, MD, PhD, ${ }^{\mathrm{c}}$ Carlos Prieto, $\mathrm{PhD},{ }^{\mathrm{p}}$ Ignacio Dávila, MD, PhD, ${ }^{\mathrm{q}}$ Miguel Marcos, MD, PhD, ${ }^{\mathrm{g}}$ Tomas Kalina, MD, PhD, ${ }^{\mathrm{h}}$ Marcela Vlkova, PhD, ${ }^{\mathrm{r}}$ Zita Chovancova, MD, PhD, ${ }^{\mathrm{r}}$ Ana Isabel Cordeiro, MD, Jan Philippé, MD, PhD,' Filomeen Haerynck, MD, PhD, ${ }^{t}$ Eduardo López-Granados, MD, PhD, ${ }^{\mathrm{e}}$ Ana E. Sousa, PhD, ${ }^{f}$ Mirjam van der Burg, PhD, ${ }^{u, v}$ Jacques J. M. van Dongen, MD, PhD, ${ }^{w_{\ddagger}}$ and Alberto Orfao, MD, PhD, ${ }^{\mathrm{a}, \mathrm{b}} \neq$ on behalf of the EuroFlow PID group Salamanca, Madrid, and Pamplona, Spain; Lisbon, Portugal; Prague and Brno, Czech Republic; Ghent, Belgium; and Rotterdam and Leiden, The Netherlands

\section{GRAPHICAL ABSTRACT}

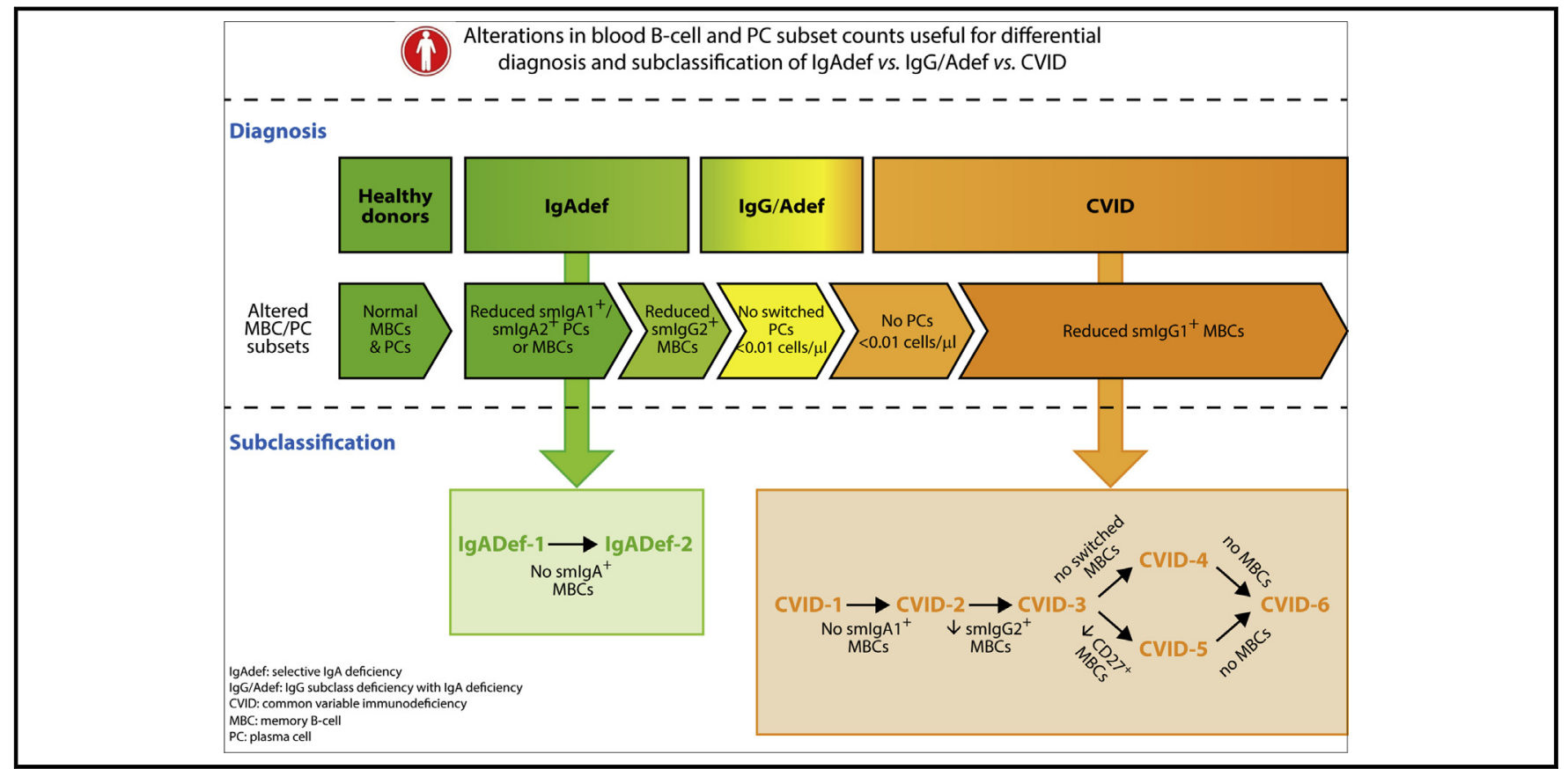

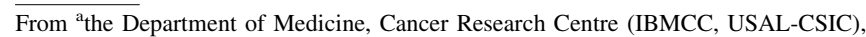
Cytometry Service (NUCLEUS), University of Salamanca (USAL), Institute of Biomedical Research of Salamanca (IBSAL), Salamanca, and ${ }^{b}$ the Biomedical Research Networking Centre Consortium of Oncology (CIBERONC), number CB16/12/00400, Instituto de Salud Carlos III, Madrid; ' Servicio de Pediatría and ${ }^{\mathrm{k} S e r}$ -

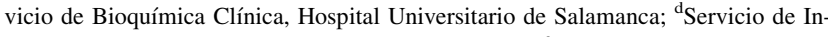
munología, Fundación Jiménez Díaz, Madrid; ${ }^{e}$ the Clinical Immunology Department, University Hospital La Paz and Physiopathology of Lymphocytes in Immunodeficiencies Group, IdiPAZ Institute for Health Research, Madrid; 'Instituto de Medicina Molecular, Faculdade de Medicina, Universidade de Lisboa, Lisbon; ${ }^{g}$ Servicio de Medicina Interna, Hospital Universitario de Salamanca, Institute for Biomedical Research of Salamanca, Department of Medicine, University of Salamanca, Sala-

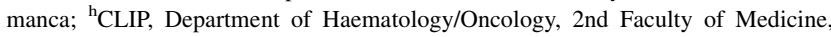
Charles University, Prague; ${ }^{i}$ NOVA Medical School/Faculdade de Ciências Médicas Universidade Nova de Lisboa, Lisbon; ${ }^{j}$ Centro de Salud Miguel Armijo, Salamanca; 'the Department of Laboratory Medicine and the Department of Respiratory Diseases and Department of Pediatrics and Genetics, University Hospital Ghent; ${ }^{\mathrm{m}}$ Servicio de Hematología, Hospital de Navarra, Pamplona; " Servicio de Hematología, Hospital Universitario de Salamanca, Institute for Biomedical Research of Salamanca, Salamanca; ${ }^{\circ}$ the Biomedical Research Networking Centre Consortium of Oncology (CIBERONC) number $\mathrm{CB} / 16 / 12 / 00233$, Instituto de salud Carlos III, Madrid ${ }^{\mathrm{p}}$ Bioinformatics service (NUCLEUS), University of Salamanca, Salamanca; ${ }^{\mathrm{q}}$ Servicio de Alergia, Hospital Universitario de Salamanca, Institute for Biomedical Research of Salamanca, Biomedical and Diagnosis Science Department, University of Salamanca (USAL), Salamanca; ${ }^{\mathrm{r}}$ the Department of Clinical Immunology and Allergology, St Anne's University Hospital, and Faculty of Medicine, Masaryk University, Brno; ${ }^{\mathrm{S}} \mathrm{Ho}-$ spital D. Estefânia, CHLC, Lisbon; "the Department of Immunology, Erasmus MC, Rotterdam; ' Department of Pediatrics, Laboratory for Immunology, Leiden University

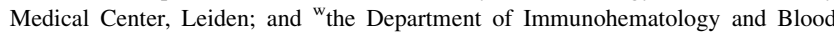
Transfusion, Leiden University Medical Center, Leiden. 
Background: Predominantly antibody deficiencies (PADs) are the most prevalent primary immunodeficiencies, but their B-cell defects and underlying genetic alterations remain largely unknown.

Objective: We investigated patients with PADs for the distribution of 41 blood B-cell and plasma cell (PC) subsets, including subsets defined by expression of distinct immunoglobulin heavy chain subclasses.

Methods: Blood samples from 139 patients with PADs, 61 patients with common variable immunodeficiency (CVID), 68 patients with selective IgA deficiency (IgAdef), 10 patients with IgG subclass deficiency with IgA deficiency, and 223 agematched control subjects were studied by using flow cytometry with EuroFlow immunoglobulin isotype staining. Patients were classified according to their B-cell and PC immune profile, and the obtained patient clusters were correlated with clinical manifestations of PADs.

Results: Decreased counts of blood PCs, memory B cells (MBCs), or both expressing distinct IgA and IgG subclasses were identified in all patients with PADs. In patients with IgAdef, B-cell defects were mainly restricted to surface membrane (sm)IgA ${ }^{+}$PCs and MBCs, with 2 clear subgroups showing strongly decreased numbers of $\operatorname{smIgA}^{+}$PCs with mild versus severe $\operatorname{smIgA}^{+} \mathrm{MBC}$ defects and higher frequencies of nonrespiratory tract infections, autoimmunity, and affected family members. Patients with IgG subclass deficiency with IgA deficiency and those with CVID showed defects in both smIgA ${ }^{+}$and smIgG $^{+}$MBCs and PCs. Reduced numbers of switched PCs were systematically found in patients with CVID (absent in 98\%), with 6 different defective MBC (and clinical) profiles: (1) profound decrease in MBC numbers; (2) defective $\mathrm{CD}^{+} 7^{+} \mathrm{MBCs}$ with almost normal $\mathrm{IgG}_{3}{ }^{+}$MBCs; (3) absence of switched MBCs; and (4) presence of both unswitched and switched MBCs without and; (5) with $\operatorname{IgG}_{2}{ }^{+} \mathrm{MBCs}$; and (6) with $\operatorname{IgA}_{1}{ }^{+}$MBCs. Conclusion: Distinct PAD defective B-cell patterns were identified that are associated with unique clinical profiles. (J Allergy Clin Immunol 2019;144:809-24.)

Key words: Immunodeficiency, primary antibody deficiency, selective IgA deficiency, common variable immunodeficiency, immunophenotyping, immunoglobulins, immunoglobulin subclasses, memory $B$ cells, plasma cells, flow cytometry, diagnosis, classification
Abbreviations used

CVID: Common variable immunodeficiency

ESID: European Society for Immunodeficiencies

GC: Germinal center

HD: Healthy donor

IgAdef: Selective IgA deficiency

IgG/Adef: IgG subclass deficiency with IgA deficiency

IgH: Immunoglobulin heavy chain

IUIS: International Union of Immunological Societies

LLN: Lower limit of normal

MBC: Memory B cell

NPV: Negative predictive value

PAD: Predominantly antibody deficiency

PC: Plasma cell

PPV: Positive predictive value

sm: Surface membrane

Predominantly antibody deficiencies (PADs) are the most prevalent primary immunodeficiencies $(50 \%$ to $70 \%$ of all primary immunodeficiencies) $)^{1,2}$ and comprise a heterogeneous spectrum of disorders with defective production of 1 or more immunoglobulin isotypes and/or immunoglobulin subclasses; the underlying pathogenic mechanisms remain largely unknown. ${ }^{1,2}$ Current classification of PADs strongly relies on the affected serum immunoglobulin heavy chain $(\operatorname{IgH})$ isotype and subclass levels and includes (1) selective IgA deficiency (IgAdef) characterized by an isolated defect of serum IgA (prevalence, approximately $1: 100-1,000$ subjects) $)^{3-5} ;$ (2) IgG subclass deficiency with $\operatorname{IgA}$ deficiency (IgG/Adef) with reduced $\operatorname{IgA}$ and 1 or more IgG subclass serum levels (approximately $15 \%$ to $20 \%$ of $\operatorname{IgA}$ deficiencies) ${ }^{6}$; and (3) common variable immunodeficiency (CVID), which is characterized by low (total) IgG serum levels, decreased IgA and/or IgM levels, and a more severe clinical presentation but a lower prevalence (approximately 1:25,000-50,000 subjects)., Although recurrent bacterial infections of the respiratory tract are the clinical hallmark of PADs, clinical manifestations vary substantially among patients, from (almost) asymptomatic cases to patients presenting with recurrent severe infections associated with other noninfectious disorders, such as autoimmunity, allergy, lymphoproliferation and organomegalies, enteropathy, and granulomatous disease. ${ }^{1,3,7-10}$
*These authors contributed equally to this work as first authors.

\$These authors contributed equally to this work as last authors.

E.B. was supported by a grant from the Junta de Castilla y León (Fondo Social Europeo, ORDEN EDU/346/2013, Valladolid, Spain). This work was supported by the CB16/ 12/00400 and CB/16/12/00233 grants (CIBERONC, Instituto de Salud Carlos III, Ministerio de Economía y Competitividad, Madrid, Spain, and FONDOS FEDER), the FIS PI12/00905-FEDER grant (Fondo de Investigación Sanitaria of Instituto de Salud Carlos III, Madrid, Spain) and a grant from Fundación Mutua Madrileña (Madrid, Spain). The coordination and innovation processes of this study were supported by the EuroFlow Consortium.

Disclosure of potential conflict of interest: E. Blanco, M. Pérez-Andrés, T. Kalina, M. Vlkova, E. López-Granados, M. van der Burg, J. J. M. van Dongen, and A. Orfao each report being one of the inventors on the EuroFlow-owned patent PCT/NL 2015/050762 (Diagnosis of primary immunodeficiencies), which is licensed to Cytognos, a company that pays royalties to the EuroFlow Consortium. J. J. M. van Dongen and A. Orfao report an Educational Services Agreement from BD Biosciences. The rest of the authors declare that they have no relevant conflicts of interest.

Received for publication April 17, 2018; Revised January 29, 2019; Accepted for publication February 1, 2019.

Available online February 28, 2019

Corresponding author: Alberto Orfao, MD, PhD, Department of Medicine, Cancer Research Center, University of Salamanca, Paseo de la Universidad de Coimbra s/n, 37007 Salamanca, Spain. E-mail: orfao@usal.es.

(d) The CrossMark symbol notifies online readers when updates have been made to the article such as errata or minor corrections 0091-6749

(C) 2019 The Authors. Published by Elsevier Inc. on behalf of the American Academy of Allergy, Asthma \& Immunology. This is an open access article under the CC BY-NC-ND license (http://creativecommons.org/licenses/by-nc-nd/4.0/).

https://doi.org/10.1016/j.jaci.2019.02.017 
Despite extensive efforts, genetic (ie, monogenic) alterations responsible for PADs are detected in less than $10 \%$ of cases. ${ }^{1,2,11}$ In such settings altered distributions of distinct blood B- and Tcell subpopulations determined by using flow cytometry might provide key (complementary) diagnostic information, particularly for patients with low serum antibody isotype levels and nonspecific clinical features. ${ }^{5,12,13}$ Thus controversial results have been reported in patients with CVID concerning the potential association between specific B-cell alterations, such as decreased (relative) numbers of $\mathrm{CD}_{2} 7^{+}$(antigen-experienced) switched B cells in blood and relevant clinical manifestations (eg, splenomegaly, granulomatous disease, and autoimmunity), ${ }^{14-18}$ whereas preservation of $\mathrm{CD} 27^{+}$class-switched memory B cells (MBCs) has been considered a surrogate marker for the ability to respond to vaccination. ${ }^{5}$ Similarly, decreased $\mathrm{CD} 27^{+}$(antigen-experienced) switched B-cell counts in blood have been associated with a worse clinical outcomes in patients with IgAdef, ${ }^{19}$ whereas decreased percentages of CD21 ${ }^{+} \mathrm{B}$ cells and increased proportions of immature/transitional B-cells have both been correlated to distinct CVID clinical profiles. ${ }^{15,18,20}$

Despite all the above associations, the actual clinical relevance of these B-cell defects in patients with PADs still remains elusive. In addition, a significant clinical and functional B-cell heterogeneity is still observed among patients who present with similar patterns of alteration of $\mathrm{B}$ cells by using flow cytometry (eg, reduced numbers of switched MBCs). ${ }^{18,21}$ This is probably due to the limited number of B-cell populations investigated, the lack of appropriate age-matched reference ranges, or both in most studies. For example, in many studies focused on antigenexperienced B cells, no distinction is made between (relative long-living) $\mathrm{MBCs}$ and (newly generated) circulating plasma cells (PCs), ${ }^{14,15,19}$ and very few reports have investigated the precise relationship between defects in specific immunoglobulin isotypes and the number of blood B cells and PCs that express them. $^{22,23}$ Moreover, thus far, no study has investigated the $\operatorname{IgG}_{1}$ to $\operatorname{IgG}_{4}$ and $\operatorname{IgA}_{1}$ and $\operatorname{IgA}_{2}$ subclass distribution within the $\mathrm{PC}$ and $\mathrm{MBC}$ compartments of patients with PADs. Finally, despite the fact that PADs can present at any age , $^{1,7,9,13}$ and major age-related differences exist in the distribution of blood B-cell subsets throughout life, ${ }^{24}$ most reports on B-cell compartments in patients with PADs do not consider (normal) age-associated variations, and only a few studies subdivided healthy donors (HDs) and patients with PADs into a few ( $\mathrm{n}=3-4)$ age groups. ${ }^{17,20,23}$ Altogether, this reflects the potential relevance of a more in-depth evaluation of the B-cell compartment and its alterations in patients with PADs versus age-matched control subjects for improved diagnosis and classification of PADs.

Here, for the first time, we investigated the distribution of 41 distinct blood B-cell and PC subsets in 139 patients with PADs versus 223 age-matched control subjects. Based on the B-cell and PC defects encountered, distinct defective immune profiles were identified that are associated with both the diagnostic subtype and clinical manifestations of PADs.

\section{METHODS}

\section{Patients and control subjects}

Overall, 139 patients with PADs $^{4}$ (mean age, $32 \pm 19$ years; range, 487 years) and 223 HDs (mean age, $39 \pm 28$ years; range, $4-99$ years) were studied. Patients with PADs were subclassified by the International Union of Immunological Societies (IUIS) ${ }^{4}$ and European Society for
Immunodeficiencies (ESID) ${ }^{5}$ criteria into 68 and 42 patients with IgAdef (mean age, $24 \pm 17$ years), respectively; 10 patients with IgG/Adef (mean age, $24 \pm 14$ years); and 61 patients with CVID (mean age, $41 \pm 17$ years). Twenty-six asymptomatic patients with IgAdef (mean age, $24 \pm 15$ years) with serum IgA levels of less than $7 \mathrm{mg} / \mathrm{dL}$ did not fulfill the ESID criteria for IgAdef and are referred to hereafter as ESID $^{-}$versus ESID ${ }^{+}$IgAdef cases. EDTA-anticoagulated blood samples were collected at 8 different sites and centrally processed in 2 of them after informed consent was provided by each subject, their legal representatives, or both. The study was approved by local ethics committees.

\section{Flow cytometric identification of blood B cells and their subsets}

Total B-cell counts and distribution of 41 distinct B-cell subsets were analyzed by using flow cytometry after staining $10^{7}$ nucleated cells with the EuroFlow 12-color immunoglobulin isotype B-cell tube (see Table E1 in this article's Online Repository at www.jacionline.org) and bulk-lyse standard operating procedure (www.EuroFlow.org), as described elsewhere. ${ }^{25,26}$ Per sample, $5 \times 10^{6}$ or more leukocytes were measured in LSRFortessa X-20 flow cytometers (Becton Dickinson Biosciences, San Jose, Calif). Instrument set-up and calibration were performed according to EuroFlow standard operating procedures (www.EuroFlow.org) ${ }^{27}$ For data analysis, Infinicyt software (Cytognos S.L., Salamanca, Spain) was used.

$\mathrm{CD} 19^{+} \mathrm{B}$-cells and PCs were both identified by using low-to-intermediate forward light scatter and sideward light scatter and subsequently subclassified into 41 different subpopulations based on their maturation stage and expression of distinct immunoglobulin isotypes and immunoglobulin subclasses, as previously described, ${ }^{24}$ by using the gating strategy detailed in the Methods section and Fig E1 in this article's Online Repository at www. jacionline.org. Briefly, the following B-cell subpopulations were defined based on their staining profile for CD19, CD38, CD24, CD21, CD27, CD5, surface membrane (sm)IgM, and smIgD: (1) $\mathrm{CD} 27^{-} \mathrm{CD} 38^{\text {hi }}$ $\mathrm{CD} 24^{\text {hi }} \mathrm{CD}^{+}{ }^{+}$smIgM $^{++} \mathrm{IgD}^{+}$immature/transitional B-cells, (2) $\mathrm{CD} 27^{-}$ $\mathrm{CD} 38^{\text {lo }} \mathrm{CD} 24^{\text {het }} \mathrm{CD}^{\text {het }}$ smIgM $^{+} \mathrm{IgD}^{++}$naive $\mathrm{B}$ lymphocytes; (3) $\mathrm{CD} 27^{+}$ $\mathrm{CD} 38^{\text {lo }}{ }^{\mathrm{CD}} 5^{-} \mathrm{CD} 24^{\text {het }} \mathrm{smIgM}^{++} \mathrm{IgD}^{+}$unswitched MBCs; (4) $\mathrm{CD} 27^{+1}$ ${ }^{-} \mathrm{CD} 38^{\text {lo }} \mathrm{CD}^{-} \mathrm{CD} 24^{\text {het }} \mathrm{smIgM}^{-} \mathrm{IgD}^{-}$switched MBCs; and (5) $\mathrm{CD}^{-} 7^{++}$ $\mathrm{CD} 38^{\text {hi }}{ }^{\mathrm{CD}} 5^{-} \mathrm{CD} 21^{-} \mathrm{CD} 24^{-}$PCs. MBCs and PCs were further subclassified according to their immunoglobulin isotypes and immunoglobulin subclasses into (1) $\mathrm{smIgM}^{++} \mathrm{IgD}^{+}, \mathrm{smIgD}^{+}$-only, $\operatorname{smIgA}_{1}{ }^{+}, \operatorname{smIgA}_{2}{ }^{+}, \mathrm{smIgG}_{1}{ }^{+}$, $\mathrm{smIgG}_{2}{ }^{+}, \mathrm{smIgG}_{3}{ }^{+}$, and $\mathrm{smIgG}_{4}{ }^{+} \mathrm{MBCs}$ and (2) $\mathrm{smIgM}^{+}$-only, $\mathrm{smIgD}^{+}$. only, $\operatorname{smIgA}{ }_{1}^{+}, \operatorname{smIgA}_{2}{ }^{+}, \operatorname{smIgG}_{1}{ }^{+}, \operatorname{smIgG}_{2}{ }^{+}, \operatorname{smIgG}_{3}{ }^{+}$, and $\operatorname{smIgG}_{4}{ }^{+}$ PCs, respectively. Finally, the above subpopulations of naive $\mathrm{B}$ lymphocytes and MBCs were placed in further subsets based on $\mathrm{CD} 21\left(\mathrm{CD} 21^{+}\right.$vs $\mathrm{CD} 21^{-}$naive and $\mathrm{MBC}$ subsets) and $\mathrm{CD} 27$ expression $\left(\mathrm{CD} 27^{+}\right.$and $\mathrm{CD} 27^{-}$ MBCs, see Fig E1). Absolute counts were calculated by using total B-cell counts based in a double-platform assay ${ }^{28}$ and used throughout the study. Intralaboratory and interlaboratory variability was assessed at the participating centers based on replicate measurements of the same samples to ensure comparable results at distinct sites (see Fig E2 in this article's Online Repository at www.jacionline.org).

\section{Statistical analyses}

Statistical analyses were performed with either the R (version 3.2.3; https:// www.r-project.org/) 29 or SPSS (version 23.0; IBM, Armonk, NY) software packages. Kruskal-Wallis and Mann-Whitney $U$ tests (for continuous variables) and $\chi^{2}$ and Fisher exact tests (for categorical variable) were used, respectively, to investigate the statistical significance (set at $P \leq .05$ ) of differences observed between groups in B-cell subset counts and clinical features. Unsupervised clustering analysis of patient data based on the K-means learning algorithm ${ }^{30}$ and Euclidean distances was performed by using blood B-cell subset absolute counts normalized by age group (see Table E2 in this article's Online Repository at www.jacionline.org) based on (previously reported) reference values of 140 age-matched subjects ${ }^{24}$ and extended here to 223 individual $-\log _{10}$ values (patient value/minimum normal value)-. Age-normalized B-cell/PC subset values per patient were represented in heat maps by using gplots (R package), ${ }^{31}$ 
and $5^{\text {th }}$ to 95 th percentile values were used to define normal ranges per age group defined by a minimum of 20 subjects (see Table E3 in this article's Online Repository at www.jacionline.org). Those B-cell and PC subsets with absolute counts that were less than the method's limit of detection (undetectable; $<0.01$ cells $/ \mu \mathrm{L}$ ) in at least 1 subject for more than 1 reference (HD) age group were excluded from the analysis (ie, IgD-only and $\mathrm{IgG}_{4}{ }^{+} \mathrm{PCs}$ and MBCs and $\mathrm{IgG}_{1}{ }^{+}, \mathrm{IgG}_{2}{ }^{+}$, and $\left.\mathrm{IgG}_{3}{ }^{+} \mathrm{PCs}\right)$.

\section{RESULTS \\ Blood B-cell and PC subset defects in patients with IgAdef}

Once compared with age-matched HDs, most patients with IgAdef displayed normal total B-cell counts (93\%), including normal immature/transitional (90\%), naive (94\%), and MBC $(87 \%)$ counts (see Table E4 in this article's Online Repository at www.jacionline.org). In contrast, numbers of (total) PCs, although being detected in every case $(\geq 0.07 \mathrm{PCs} / \mu \mathrm{L})$, were decreased in $49 \%$ of patients (Fig 1 and see Table E4). When MBCs and PCs were dissected according to their pattern of expression of immunoglobulin subclasses, a greater frequency of altered cases was observed. Thus $\operatorname{smIgA}_{1}{ }^{+}$and/or $\operatorname{smIgA}{ }_{2}^{+}$ PC counts were found to be reduced in blood in $97 \%$ of cases, with still detectable residual $\mathrm{smIgA}^{+} \mathrm{PCs}$ in $38 \%$ of the patients (PCs expressing both IgA subclasses were found in $26 \%$, smIgA $1^{+}$-only subclasses were found in $9 \%$, and $\operatorname{smIgA}_{2}{ }^{+}$only subclasses were found in $3 \%$ of all patients with IgAdef).

In line with these findings, reduced $\operatorname{smIg\mathrm {A}_{1}}{ }^{+}$and/or $\mathrm{smIgA}_{2}{ }^{+}$ MBC counts were also observed in virtually all patients with IgAdef $(99 \%)$, although still present in half $(50 \%)$ of them (both smIgA $_{1}{ }^{+}$and $\operatorname{smIgA}_{2}{ }^{+}$MBCs were detected in $40 \%$ and smIgA ${ }_{1+}$-only MBCs were detected in $10 \%$ of all patients with IgAdef; Fig 2 and see Table E4). Thus decreased $\operatorname{smIgA}_{1}{ }^{+}$or $\mathrm{smIgA}_{2}{ }^{+} \mathrm{MBC}$ counts showed a sensitivity of $99 \%$ with a negative predictive value (NPV) of $100 \%$ (see Table E5 in this article's Online Repository at www.jacionline.org), although when combined with decreased $\mathrm{smIgA}_{1}{ }^{+}$or $\mathrm{smIgA}_{2}{ }^{+} \mathrm{PC}$ counts, reached a 100\% sensitivity and NPV (see Table E6 in this article's Online Repository at www.jacionline.org). In turn, absence of the above MBC or PC subpopulations showed a specificity of $100 \%$ and positive predictive value (PPV) of $98 \%$ for identification of patients with IgAdef (see Table E6). In contrast, smIgG ${ }^{+}$PCs were present in virtually every patient with $\operatorname{IgAdef}(91 \%)$, with normal smIgG ${ }^{+}$PC counts in $71 \%$ of them. Similarly, smIgG to $\mathrm{smIgG}_{3}{ }^{+} \mathrm{MBC}$ counts were only decreased in $13 \%$ or fewer patients (Fig 1 and see Fig E3 and Table E4).

\section{Blood B-cell and PC subset defects in patients with IgG/Adef}

Similarly to patients with IgAdef, total peripheral blood B-cell counts, including immature/transitional, naive and MBC counts, were within the normal range in most patients with $\mathrm{IgG} / \mathrm{Adef}$ (90\%, Fig 2 and see Table E4); in contrast, decreased PC counts were observed in $90 \%$ of patients with IgG/Adef, mostly because of a significant decrease in both $\mathrm{smIgA}^{+}$and $\mathrm{smIgG}^{+} \mathrm{PC}$ counts ( $100 \%$ and $90 \%$, respectively), which were undetectable in $90 \%$ and $50 \%$ of cases, respectively. Although total blood MBC counts were within the normal range in $70 \%$ of patients with $\mathrm{IgG} / \mathrm{Adef}$ showed decreased $\operatorname{smIgA}_{1}{ }^{+} \mathrm{MBC}$ and/or $\operatorname{smIg\mathrm {A}_{2}}{ }^{+} \mathrm{MBC}$ counts in association with decreased $\mathrm{smIgG}_{2}{ }^{+} \mathrm{MBC}$ counts; meanwhile,
$\mathrm{smIgG}_{1}{ }^{+}$and $\mathrm{smIgG}_{3}{ }^{+} \mathrm{MBC}$ counts were normal in $80 \%$ and $90 \%$ of patients with IgG/Adef, respectively (Fig 1 and see Fig E3 and Table E4).

Based on these results, the observation of undetectable PCs combined with decreased $\mathrm{smIgG}_{2}{ }^{+} \mathrm{MBC}$ counts also showed a high sensitivity (90\%), specificity (96\%), and NPV (100\%) for IgG/Adef in addition to those MBC and PC populations that identified IgAdef. In contrast, the PPV was only $50 \%$ because of the low number of patients with IgG/Adef analyzed (Fig 1 and see Tables E6 and E7 in this article's Online Repository at www. jacionline.org).

\section{Blood B-cell and PC subset defects in patients with CVID}

In contrast to patients with IgAdef, total B-cell and PC counts were decreased in around half $(51 \%)$ and the majority $(98 \%)$ of patients with CVID, respectively $(P<.001$ vs patients with IgAdef). In addition, immature/transitional and naive B lymphocytes were decreased in $42 \%$ and $43 \%$ of patients with CVID, mostly at the expense of $\mathrm{CD} 21^{+} \mathrm{B}$ cells (Fig 2 and see the Results section, Fig E4, and Table E4 in this article's Online Repository at www.jacionline.org), with only $10 \%$ and $3 \%$ of patients with CVID showing undetectable immature/transitional and naive $\mathrm{B}$ cells, respectively (Fig 2 and see Table E4). Reduced $\mathrm{smIgA}_{1}{ }^{+}$and/or $\operatorname{smIgA}_{2}{ }^{+}$PC counts were found in all patients with CVID, being undetectable in virtually every (98\%) case. In line with these findings, only $2 \%$ of patients with CVID showed circulating $\mathrm{smIgG}^{+}$PCs (Fig 1 and see Fig E3 and Table E4). Thus the absence of switched PCs was highly accurate $(100 \%$ specificity, $100 \% \mathrm{PPV}$, and $100 \% \mathrm{NPV}$, with a sensitivity of 98\%) for identification of CVID (see Table E8 in this article's Online Repository at www.jacionline.org). Of note, no other parameter or combination of parameters showed an improved sensitivity, specificity, PPV, and NPV for identification of CVID than the absence of switched PCs or the lack of smIgA $_{2}{ }^{+}$PCs (see Table E6). However, the lack of switched PCs was not specific enough for an accurate differential diagnosis among distinct PAD subgroups because $9 \%$ of patients with IgAdef and $50 \%$ of patients with IgG/Adef also had undetectable switched PCs. Because of this, for a clear-cut discrimination among distinct PAD diagnostic categories, the lack of switched PCs needs to be combined with the absence or decrease in other B-cell subsets in patients with CVID that are typically normal among patients with IgAdef and those with IgG/Adef (eg, $\mathrm{smIgG}_{1}{ }^{+}$or $\mathrm{smIgG}_{2}{ }^{+} \mathrm{MBCs}$, or total PCs; Fig 1 and see Table E4). Interestingly, the (small) subgroup of patients with IgAdef who had undetectable switched PCs also had lower serum IgG levels at diagnosis (data not shown).

Finally, despite abnormally low total MBC counts being observed in most patients with CVID (70\%) and being undetectable $(<0.01 \mathrm{MBCs} / \mu \mathrm{L})$ in only $13 \%$ of cases, the degree of involvement of MBCs expressing different immunoglobulin isotypes and immunoglobulin subclasses varied significantly. Thus reduced $\mathrm{smIgA}_{1}{ }^{+}$and/or $\operatorname{smIgA}_{2}{ }^{+} \mathrm{MBC}$ counts were observed in virtually all patients with CVID (98\%), being absent in most of them (80\%). Regarding MBC subsets expressing distinct IgG subclasses, patients with CVID more frequently showed decreased or absent $\operatorname{smIgG}_{2}{ }^{+}(95 \%$ and $67 \%$ of patients, respectively) than $\operatorname{smIgG}_{1}{ }^{+} \mathrm{MBC}$ counts $(90 \%$ and $33 \%[P>.05$ 



B

\begin{tabular}{|c|c|c|c|c|}
\hline Criteria for differential diagnosis & $\begin{array}{c}\text { HD } \\
(n=223)\end{array}$ & $\begin{array}{l}\text { IgAdef } \\
(n=68)\end{array}$ & $\begin{array}{c}\text { IgG/Adef } \\
(n=10)\end{array}$ & $\begin{array}{l}\text { CVID } \\
(n=61)\end{array}$ \\
\hline \multicolumn{5}{|l|}{ HD vs. PAD } \\
\hline Strongly $\downarrow$ smlgA1 ${ }^{+} / \mathrm{smlgA2}^{+} \mathrm{PCS}$ or MBCs & $\begin{array}{c}\text { No } \\
(0 / 223)\end{array}$ & $\begin{array}{c}\text { YES } \\
(68 / 68) \\
-\end{array}$ & $\begin{array}{c}\text { YES } \\
(10 / 10)\end{array}$ & $\begin{array}{c}\text { YES } \\
(61 / 61)\end{array}$ \\
\hline TOTAL & $0 / 223$ & $68 / 68$ & $10 / 10$ & $61 / 61$ \\
\hline \multicolumn{5}{|l|}{ IgAdef vs. CVID } \\
\hline $\begin{array}{l}\text { Undetectable smlgG2 }{ }^{+} \mathrm{MBCs} \\
\quad \text { or } \\
\text { Undetectable total PCs }(<0.01 \text { cells } / \mu \mathrm{L})\end{array}$ & & $\begin{array}{l}\text { No } \\
(0 / 68) \\
\text { NO } \\
(0 / 68)\end{array}$ & $\begin{array}{l}\text { NO } \\
(3 / 10) \\
\text { YES } \\
(5 / 10)\end{array}$ & $\begin{array}{c}\text { YES } \\
(41 / 61) \\
\text { YES } \\
(55 / 61)\end{array}$ \\
\hline TOTAL & & $0 / 68$ & $6 / 10$ & $59 / 61$ \\
\hline \multicolumn{5}{|l|}{ IgAdef vs. IgG/Adef } \\
\hline $\begin{array}{l}\downarrow \text { smlgG2 }^{+} \text {MBCs } \\
\quad \text { or } \\
\text { Undetectable total PCs }(<0.01 \text { cells } / \mu \mathrm{L})\end{array}$ & & $\begin{array}{l}\text { No } \\
(8 / 68) \\
\text { No } \\
(0 / 68) \\
-1 .-1 .\end{array}$ & $\begin{array}{l}\text { YES } \\
(8 / 10) \\
\text { YES } \\
(5 / 10) \\
-\end{array}$ & $\begin{array}{c}\text { YES } \\
(58 / 61) \\
\text { YES } \\
(55 / 61)\end{array}$ \\
\hline TOTAL & & $8 / 68$ & 9/10 & $61 / 61$ \\
\hline \multicolumn{5}{|l|}{ CVID vs. IgG/Adef } \\
\hline $\begin{array}{l}\text { Undetectable switched PCs }(<0.01 \text { cells } / \mu \mathrm{L}) \\
\text { and } \\
\downarrow \text { smlgG1 }\end{array}$ & & $\begin{array}{l}\text { No } \\
(6 / 68) \\
\text { No } \\
(9 / 68)\end{array}$ & $\begin{array}{l}\text { YES } \\
(5 / 10) \\
\text { No } \\
(2 / 10) \\
-\end{array}$ & $\begin{array}{c}\text { YES } \\
(60 / 61) \\
\text { YES } \\
(55 / 61)\end{array}$ \\
\hline TOTAL & & $0 / 68$ & $1 / 10$ & $54 / 61$ \\
\hline
\end{tabular}

FIG 1. Alterations in blood B-cell and PC subset counts useful for the diagnosis of PADs and for the differential diagnosis of IgAdef versus IgG/Adef versus CVID. A, Scheme illustrating the most useful peripheral blood B-cell subset alterations for the diagnosis of PADs (vs HDs; strongly reduced: absolute numbers lower than the minimum value in HDs) and the differential diagnosis of patients with IgAdef versus patients with IgG/Adef versus patients with CVID are shown. As displayed, these criteria showed a $100 \%$ and approximately $98 \%$ accuracy in the diagnosis of PADs and the discrimination between IgAdef and CVID, respectively, whereas approximately $10 \%$ of cases within both diagnostic subgroups overlapped with $10 \%$ and $10 \%$ of patients with IgG/Adef, respectively. B, Most useful peripheral blood B-cell subset criteria for the diagnosis of PAD versus HDs and the distinction between patients with IgAdef versus patients with CVID, patients with IgAdef versus patients with IgG/Adef, and patients with CVID versus patients with IgG/Adef are shown, together with the number of cases within the different diagnostic categories that fulfilled these criteria. 


\section{A Major PB B-cell/PC subsets}

\% Decreased:

IgAdef IgG/Adef CVID

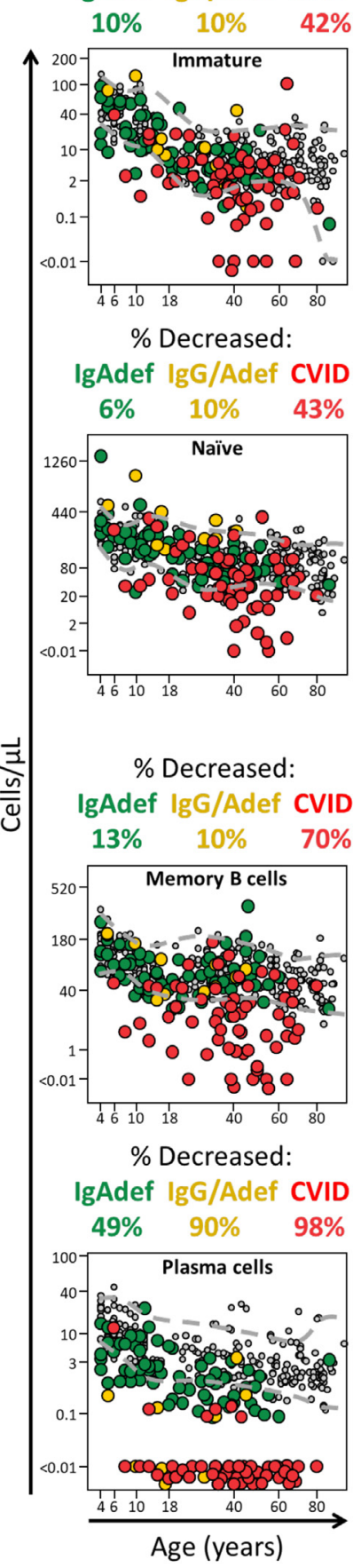

\section{B Memory B-cell subsets}

\% Decreased: IgAdef IgG/Adef CVID

$\%$ Decreased: IgAdef IgG/Adef CVID

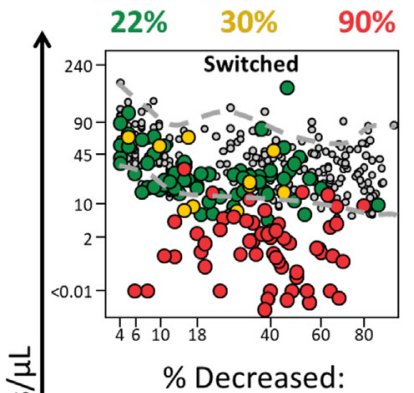
96\% $\quad 70 \% \quad 95 \%$

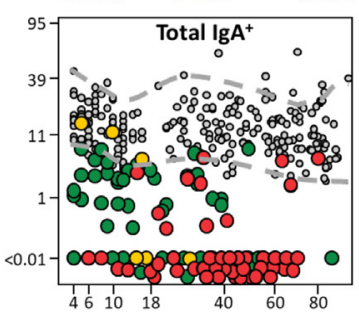

$\%$ Decreased:

IgAdef IgG/Adef CVID

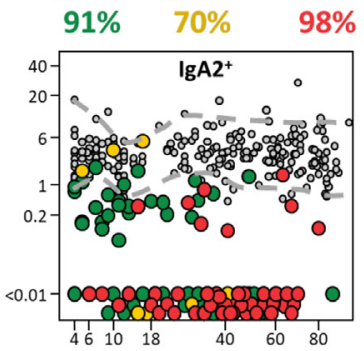

C Plasma cell subsets

\% Decreased:

$\%$ Decreased:

IgAdef IgG/Adef CVID

IgAdef IgG/Adef CVID

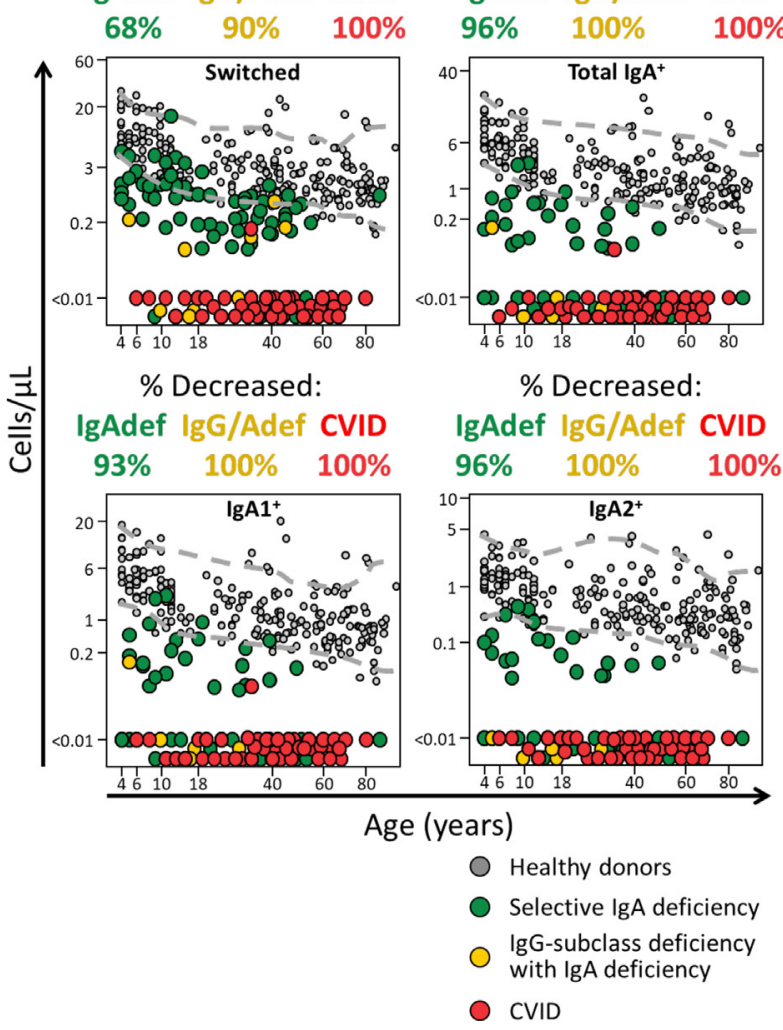

FIG 2. Absolute counts of distinct maturation-associated subpopulations of blood $B$ cells and PCs (A) and total switched, total $\lg A$, and $\lg A$ subclass subsets of $M B C s(B)$ and $P C s(C)$ in patients with $\lg A d e f(n=68)$, patients with IgG/Adef $(n=10)$, and patients with CVID $(n=61)$ versus HDs $(n=223)$ grouped by age. Individual cases are represented as green dots (IgAdef), yellow dots (IgG/lgAdef), red dots (CVID), and gray dots (HDs). Dotted gray lines represent age-associated reference 5th and 95th values. Percentages of patients with reduced numbers compared with reference values per age group are depicted above each plot by using the same color code. 
and $P<.001]$, respectively) and $\mathrm{smIgG}_{3}{ }^{+} \mathrm{MBC}$ counts $(61 \%$ and $23 \%$, respectively; $P<.001$; Fig 1 and see Fig E3 and Table E4).

\section{Classification of patients with PADs based on blood $B-c e l l$ and PC subset immune profiles}

Unsupervised clustering analysis identified 5 major immune profiles of altered blood B-cell and PC subset counts in patients with PADs (classification criteria are provided in Table I), which were closely related to the IUIS diagnostic categories of PADs and are termed hereafter PAD-1 to PAD-5 (Fig 3, A). ${ }^{4}$ Thus patients with IgAdef were split between the PAD-1 and PAD-2 clusters (with 1 outlier in PAD-3), and patients with IgG/Adef were split between the PAD-1, PAD-2, and PAD-3 groups, whereas most (54/61) patients with CVID fell into the PAD-3, PAD-4, and PAD- 5 clusters, with 7 of 61 outliers falling into the PAD-1 and PAD-2 groups (Fig 3, $A$ ).

In detail, PAD-1 included 40 patients with reduced but detectable numbers of $\operatorname{smIgA}{ }^{+}$PCs and/or smIgA ${ }^{+}$MBCs $\left(\mathrm{smIgA}^{+}\right.$ MBCs and smIgA ${ }^{+}$PCs ranging from $<12$-fold below the lower limit of normal [LLN] and undetectable to virtually normal counts, respectively). Thirty-two (80\%) of 40 PAD-1 cases had been given a previous diagnosis of IgAdef and 2 (5\%) of IgG/ Adef, and $6(15 \%)$ were patients with CVID with decreased but detectable numbers of $\operatorname{IgA}_{1}{ }^{+}$or $\operatorname{IgA}_{2}{ }^{+}$MBCs with limited effect on the overall number of smIgA ${ }^{+}$MBCs (never decreased $>12$ times the LLN) and virtually normal $\mathrm{IgG}_{1}{ }^{+}$to $\mathrm{IgG}_{3}{ }^{+} \mathrm{MBC}$ counts.

PAD-2 was characterized by severely decreased numbers of smIgA ${ }^{+}$MBCs ( $>40$ times below the LLN; absent in 37 of 39 patients) and absence of smIgA ${ }^{+}$PCs but (similarly to PAD-1) virtually normal $\mathrm{smIgG}_{1}{ }^{+}$to $\mathrm{smIgG}_{3}{ }^{+} \mathrm{MBC}$ counts. This PAD-2 cluster included $35(90 \%)$ patients with IgAdef, 3 (7.5\%) patients with IgG/Adef, and $1(2.5 \%)$ patient with CVID who lacked PCs and $\mathrm{smIgA}{ }^{+}$MBCs but had normal $\mathrm{smIgG}^{+} \mathrm{MBC}$ numbers.

PAD-3 cases consisted of patients with severely decreased switched $\operatorname{smIgG}^{+}$and smIgA ${ }^{+}$PC counts (absent in 34/35 cases) and $\mathrm{smIg \textrm {A } _ { 1 }}{ }^{+} / \mathrm{smIgA}_{2}{ }^{+} \mathrm{MBC}$ counts (absent in 30/36 cases) but presenting with a heterogeneous defect on $\mathrm{IgG}^{+} \mathrm{MBCs}$, consisting of severely reduced $\mathrm{smIgG}_{2}{ }^{+} \mathrm{MBC}$ counts (absent in 19/36), with a milder decrease in $\mathrm{smIgG}_{1}{ }^{+}(86 \%$ of cases) and particularly $\mathrm{smIgG}_{3}{ }^{+}$(39\% of cases) $\mathrm{MBC}$ counts. This subgroup included 30 patients with CVID (83\%), 5 patients with IgG/ Adef (14\%), and 1 patient with IgAdef (3\%).

Finally, all PAD-4 and PAD-5 cases had undetectable $\mathrm{smIgG}_{2}{ }^{+}$ MBCs (14/14 cases) with severely reduced $\operatorname{smIgG}_{1}{ }^{+} \mathrm{MBC}$ counts (14/14; absent in 9/14 cases; PAD-4) or no MBCs at all (PAD-5), except for 2 PAD- 5 cases who showed detectable $\mathrm{IgG}_{3}{ }^{+} \mathrm{MBCs}$ at levels of greater than 15-fold below the LLN; all PAD-4 and PAD5 cases corresponded to CVID.

\section{Blood B-cell and PC immune profiles in patients with IgAdef}

Patients with IgAdef were split into 2 subgroups termed hereafter IgAdef-1 and IgAdef-2 (classification criteria are provided in Table I) with different patterns of alteration of $\operatorname{smIgA^{+}}$ MBCs (Fig 3, B): $\operatorname{smIgA}_{1}{ }^{+}$and/or $\operatorname{smIgA}{ }_{2}{ }^{+}$MBCs were present in the IgAdef-1 group, whereas they were virtually absent in IgAdef- 2 cases (Fig 4, B, and Figs E5, $A$, and E6 in this article's Online Repository at www.jacionline.org). Interestingly, these 2 subgroups did not show a strong association with the ESID diagnostic criteria ${ }^{5}$ for clinical IgAdef, which were met in $53 \%$ of IgAdef-1 cases versus $69 \%$ of IgAdef- 2 cases $(P>.05$; see Table E9, $A$, in this article's Online Repository at www. jacionline.org). Of note, IgAdef-1 cases were older than IgAdef- 2 cases both at the time of analysis $(31 \pm 19$ years vs $17 \pm 13$ years, respectively; $P=.001)$ and at diagnosis $(28 \pm 19$ years vs $14 \pm 13$ years, respectively; $P=.006)$, with a similar male/female distribution. Despite no differences being observed in IgM serum levels at diagnosis, serum IgG levels were slightly lower in IgAdef- 1 versus IgAdef- 2 cases $(1305 \pm 290$ vs $1467 \pm 232 \mathrm{mg} / \mathrm{dL}, P=.03)$. In turn, although around one third of both IgAdef- 1 and IgAdef- 2 cases had a past history of recurrent respiratory tract infections at presentation, IgAdef- 2 cases showed a greater frequency of other (recurrent) infections (17\% vs $0 \%$, respectively; $P=.02)$, tissuespecific autoimmunity ( $31 \%$ vs $6 \%$, respectively; $P=.01$ ), and other family members affected (22\% vs $3 \%$, respectively; $P=.03$; Fig 5, A, and see Table E10 in this article's Online Repository at www.jacionline.org).

\section{Blood B-cell and PC immune profiles in patients with CVID}

Overall, 6 subgroups of CVID (designated hereafter as CVID-1 to CVID-6) with different patterns of altered B-cell subsets and complete absence of switched PCs in $98 \%$ of cases (classification criteria are provided in Table I) were identified (Figs 3, $C$, and 4, $C$, and see Figs E5, $B$, and E6).

The CVID-1 and CVID-2 groups included patients with both detectable smIgMD ${ }^{+} \mathrm{MBC}$ and switched $\mathrm{MBC}$ of all $\mathrm{smIgG}_{1}$ to smIgG $_{3}$ subclasses, with CVID-1 (but not CVID-2) cases also presenting normal or slightly reduced $\mathrm{IgA}_{1}{ }^{+} \mathrm{MBC}$ counts. In contrast, CVID-3 cases showed a more severe $\mathrm{smIgG}_{2}{ }^{+} \mathrm{MBC}$ defect ( $>4$-fold below the LLN), frequently with undetectable $(<0.01$ cells $/ \mu \mathrm{L}) \mathrm{smIgG}_{2}{ }^{+}$MBCs $(17 / 22$ cases $)$. CVID- 4 cases had no switched MBCs, whereas CVID-5 cases showed more severe defects involving all $\mathrm{CD} 27^{+} \mathrm{MBC}$ subsets $(\geq 6$-fold below the LLN) but almost normal $\mathrm{CD}_{2} 7^{-} \mathrm{smIgG}_{3}{ }^{+} \mathrm{MBC}$ counts. Finally, CVID-6 cases had severely decreased switched and unswitched MBC counts, including 0.06 or fewer $\mathrm{IgG}_{3}{ }^{+} \mathrm{MBCs} /$ $\mu \mathrm{L}$ (>15-fold below the LLN; Figs 3, $C$, and 4, $C$ ).

Overall, a close association between the CVID-1 and CVID-6 clusters and the EUROclass classification (see Table E11 in this article's Online Repository at www.jacionline.org) ${ }^{18}$ of CVID was observed. Thus EUROclass $\mathrm{smB}^{+}$patients were subclassified here into the CVID-1 (58\%), CVID-2 (17\%), and CVID-3 (25\%) clusters, depending on their normal versus low $\operatorname{smIgA}^{+}$and $\mathrm{smIgG}_{2}{ }^{+}$MBC counts. EUROclass $\mathrm{B}^{-}$patients were included in our CVID-6 cluster, except for 2 cases with less than $1 \%$ peripheral blood B cells but preserved MBC counts, who were thereby classified as CVID-4 and CVID-5, respectively. In fact, in 8 of 9 patients classified as $\mathrm{B}^{-}$, we could identify naive B cells, and in 4 of 9 cases we could also identify MBCs, despite these cells being severely decreased in 2 of them. In contrast, EUROclass $\mathrm{smB}^{-}$patients split across the different CVID-1 to CVID6 clusters: CVID-1, 2.5\%; CVID-2, 10\%; CVID-3, 47.5\%; CVID-4, 12.5\%; CVID-5, 20\%; and CVID-6, 7.5\% of smB cases (Fig 3, $C$, and see Table E9, B). Inclusion of other EUROclass parameters, such as CD21 expression (see Table E9, $B$ ) or immature/transitional B-cell counts did not result in significantly 
TABLE I. Criteria used for subclassification of patients with PAD, patients with IgAdef, and patients with CVID into the PAD-1 to PAD-5, IgAdef-1 to IgAdef-2, and CVID-1 to CVID-6 clusters, respectively

\begin{tabular}{|c|c|c|c|c|c|c|}
\hline \multirow[b]{2}{*}{ Clusters } & \multicolumn{6}{|c|}{ MBCs } \\
\hline & Total MBCs & $\mathrm{CD}^{2} 7^{+} \mathrm{MBCs}$ & $\mathrm{CD}_{21}{ }^{+} \mathrm{MBCs}$ & $\mathrm{smlgM}^{++} \operatorname{lgD}{ }^{+}$MBCs & Switched MBCs & $\mathrm{smlg}^{+}$MBCs \\
\hline PAD-1 & Normal or $\downarrow<2$-fold & & & Normal or $\downarrow<1.4$-fold & Normal or $\downarrow<3$-fold & $\begin{array}{l}\text { Normal or } \\
\downarrow<<12 \text {-fold }\end{array}$ \\
\hline PAD-2 & Normal or $\downarrow<1.4$-fold & & & Normal or $\downarrow<1.1$-fold & Normal or $\downarrow<2$-fold & $\begin{array}{r}\downarrow>40 \text {-fold or } \\
\text { undetectable }\end{array}$ \\
\hline PAD-3 & Normal or $\downarrow<10$-fold & & & Normal or $\downarrow<2$-fold $\dagger$ & $\begin{array}{l}\text { Normal or } \\
\quad \downarrow<100 \text {-fold }\end{array}$ & $\begin{array}{l}\downarrow>2 \text {-fold or } \\
\quad \text { undetectable }\end{array}$ \\
\hline PAD-4 & $\downarrow 1.4-46$ fold & & & $\begin{array}{l}\downarrow \geq 2 \text {-fold or } \\
\quad \text { undetectable } \S\end{array}$ & $\begin{array}{l}\downarrow>12 \text {-fold or } \\
\quad \text { undetectable }\end{array}$ & Undetectable \\
\hline PAD-5 & $\begin{array}{c}\downarrow>500 \text {-fold or } \\
\text { undetectable }\end{array}$ & & & Undetectable & $\begin{array}{r}\downarrow>190 \text {-fold or } \\
\text { undetectable }\end{array}$ & Undetectable \\
\hline IgAdef-1 & & & & & & $\begin{array}{c}\text { Normal or } \\
\downarrow<12 \text {-fold }\end{array}$ \\
\hline IgAdef-2 & & & & & & $\begin{array}{l}\downarrow>40 \text {-fold or } \\
\text { undetectable }\end{array}$ \\
\hline CVID-1 & Normal & Normal or $\downarrow<1.4$-fold & $\begin{array}{l}\text { Normal or } \\
\quad \downarrow<1.8 \text {-fold }\end{array}$ & Normal or $\downarrow<1$.4-fold & Normal or $\downarrow<3$-fold & \\
\hline CVID-2 & Normal & Normal & Normal & Normal & Normal or $\downarrow<5$-fold & \\
\hline CVID-3 & Normal or $\downarrow<5$-fold\# & Normal or $\downarrow<6$-fold\# & $\begin{array}{l}\text { Normal or } \\
\quad \downarrow<8 \text {-fold } \#\end{array}$ & Normal or $\downarrow<3$-fold & $\downarrow>3-100$ fold & \\
\hline CVID-4 & $\downarrow 1.4-30$ fold & $\downarrow 1.3-30$ fold & $\downarrow 1.5-35$ fold & Normal or $\downarrow<14$-fold & Undetectable & \\
\hline CVID-5 & $\downarrow 5-45$ fold & $\begin{array}{l}\downarrow \geq \mathbf{6} \text {-fold or } \\
\text { undetectable }\end{array}$ & $\downarrow$ 8-1000-fold & $\begin{array}{l}\downarrow \geq 3 \text {-fold or } \\
\quad \text { undetectable }\end{array}$ & $\downarrow>2-80$ fold & \\
\hline CVID-6 & $\begin{array}{c}\downarrow>500 \text {-fold or } \\
\text { undetectable }\end{array}$ & Undetectable & $\begin{array}{l}\downarrow>780 \text {-fold to } \\
\text { undetectable }\end{array}$ & Undetectable & $\begin{array}{r}\downarrow>185 \text {-fold or } \\
\text { undetectable }\end{array}$ & \\
\hline
\end{tabular}

B-cell subpopulations that were not required for patient subclassification are plotted as empty cells. Undetectable is defined as less than 0.01 cells/ $\mu$ L. The most relevant subsets for discrimination between 2 or more subgroups are highlighted in boldface.

*Less than $15 \%$ of cases showed reduced $\mathrm{smIgG}_{2}{ }^{+} \mathrm{MBC}$ counts systematically associated with the presence of switched PCs or normal to less than 2 -fold reduced smIgA ${ }^{+} \mathrm{MBC}$ counts.

$\dagger$ Those cases with smIgMD ${ }^{+} \mathrm{MBC}$ counts reduced more than 2-fold systematically had normal $\mathrm{smIgG}_{3}{ }^{+} \mathrm{MBC}$ or detectable smIgG ${ }_{2}^{+} \mathrm{MBC}$ counts .

$\ddagger$ One case had detectable switched PCs (55-fold below the LLN) associated with decreased $\operatorname{smIgG}_{1}^{+}\left(>1.5\right.$-fold) and smIgG ${ }_{2}^{+} \mathrm{MBC}^{+}$counts and undetectable smIgA ${ }^{+} \mathrm{MBCs}$ §One case had normal values associated with undetectable switched MBCs.

$\|$ Reduced $\operatorname{smIgA}{ }_{1}^{+}$or $\operatorname{smIgA}_{2}{ }^{+} \mathrm{PC}$ counts were observed in all patients with IgAdef except 2 patients who had decreased smIgA ${ }^{+}$MBC counts.

TOne CVID case showed detectable but reduced switched PC counts.

${ }^{\#}$ When $\mathrm{smIgG}_{2}{ }^{+} \mathrm{MBC}$ sere present, these subsets were systematically decreased.

different distributions of $\mathrm{smB}^{-}$patients across our CVID-1 to CVID-6 clusters (data not shown).

When considering the 6 CVID clusters, no overall differences were observed among them regarding age (at time of study and at diagnosis) and immunoglobulin serum levels, whereas significant differences were found in the frequency of autoimmunity $(P=.02)$, autoimmune cytopenias $(P=.02)$, and (a statistical trend) hepatomegaly $(P=.06)$. Subsequent pairwise comparisons confirmed a similar age and sex distribution and frequency of recurrent infections (range, $83 \%$ to $100 \%$ ) was observed among the 6 CVID clusters, except for CVID-6 cases, who were significantly older than CVID-2 cases $(P=.04)$. In addition, no differences were observed regarding serum immunoglobulin levels at diagnosis and the clinical manifestations of the disease among patients with preserved $\mathrm{smIgG}_{1}{ }^{+}$MBCs (CVID-1, CVID-2, and CVID-3 cases). Conversely, all CVID-4 cases presented with autoimmunity versus $25 \%$ in CVID-1 $(P=.009), 33 \%$ in CVID-2 $(P=.03)$, and 50\% in CVID-3 $(P=.04)$ cases, including a greater frequency of autoimmune cytopenias $(67 \%$ vs $0 \%$ in CVID- 1 and CVID-2 cases and 20\% in CVID-3 cases, $P \leq .05$ ) and a tendency $(P>.05)$ toward a greater frequency of systemic autoimmunity (50\% vs $25 \%$ in CVID-1, $0 \%$ in CVID-2, and $10 \%$ in CVID-3 cases). Although systemic autoimmunity was not detected among CVID-5 cases ( $P=.04$ vs CVID-4 cases), these cases more frequently had other adverse clinical features, such as hepatomegaly (44\% vs $5 \%$ in CVID-3 cases, $P=.02$ ), autoimmunity ( $89 \%$ vs $25 \%$ in CVID- 1 cases $[P=.01], 33 \%$ in CVID-2 cases $[P<.05]$, and 50\% in CVID-3 cases $[P=.05]$ ), and cytopenias (44\% vs $0 \%$ in CVID- 1 cases, $P=.05$ ).

Finally, CVID-6 cases displayed a mixed clinical profile between CVID-4 and CVID-5 cases, with a high frequency of autoimmune cytopenias (50\%), as well as hepatomegaly $(56 \%)$, bronchiectasis (80\%), and enteropathy (78\%; Fig 5, B). Additionally, CVID-6 cases presented with granulomatous disease more frequently than all other CVID patient groups (30\% vs $0 \%$ to $15 \%, P=.06$; Fig 5, $B$, and see Table E12 in this article's Online Repository at www.jacionline.org).

\section{DISCUSSION}

Current IUIS and ESID guidelines for diagnosis and classification of PADs rely on antibody serum levels, response to 


\begin{tabular}{|c|c|c|c|c|c|}
\hline \multicolumn{4}{|c|}{ MBCs } & \multicolumn{2}{|c|}{ PCs } \\
\hline $\mathrm{smlgA}_{1}{ }^{+} \mathrm{MBCs}$ & $\mathrm{smlgG}_{3}{ }^{+} \mathrm{MBCs}$ & $\mathrm{smlgG}_{1}{ }^{+} \mathrm{MBCs}$ & $\mathrm{smlgG}_{2}{ }^{+} \mathrm{MBCs}$ & Switched PCs & smlgA ${ }^{+}$PCs \\
\hline & Normal or $\downarrow<2$-fold & Normal or $\downarrow<3$-fold & Normal* & $\begin{array}{l}\text { Detectable in } \\
>80 \% \text { of cases }\end{array}$ & $\begin{array}{l}\downarrow \text { or undetectable in } \\
>90 \% \text { of cases }\end{array}$ \\
\hline & Normal or $\downarrow<2$-fold & Normal or $\downarrow<1.3$-fold & Normal* & $\begin{array}{l}\text { Detectable in } \\
>\mathbf{8 0 \%} \text { of cases }\end{array}$ & Undetectable \\
\hline & Normal or $\downarrow<12$-fold & Normal or $\downarrow<65$-fold & $\begin{array}{l}\downarrow>1.4 \text {-fold or } \\
\text { undetectable }\end{array}$ & Undetectable & \\
\hline & $\begin{array}{l}\downarrow>1.2 \text {-fold or } \\
\text { undetectable }\end{array}$ & $\begin{array}{c}\downarrow>13 \text {-fold or } \\
\text { undetectable }\end{array}$ & Undetectable & Undetectable & \\
\hline & $\begin{array}{l}\quad>>15 \text {-fold or } \\
\text { undetectable }\end{array}$ & Undetectable & Undetectable & Undetectable & \\
\hline & & & & & $\downarrow$ or undetectable $\|$ \\
\hline $\begin{array}{l}\downarrow>\text { 34-fold or } \\
\text { undetectable }\end{array}$ & & Normal or $\downarrow<4$-fold & Normal or $\downarrow<12$-fold & Undetectable & \\
\hline $\begin{array}{l}\quad \downarrow>9 \text {-fold or } \\
\text { undetectable }\end{array}$ & & $\downarrow 2$-65-fold & $\begin{array}{l}\downarrow>4 \text {-fold or } \\
\text { undetectable }\end{array}$ & Undetectable & \\
\hline Undetectable & & Undetectable & Undetectable & Undetectable & \\
\hline $\begin{array}{l}\downarrow>20 \text {-fold or } \\
\text { undetectable }\end{array}$ & & $\downarrow>9$-fold or undetectable & $\begin{array}{l}\quad \downarrow>80 \text {-fold or } \\
\quad \text { undetectable }\end{array}$ & Undetectable & \\
\hline Undetectable & & Undetectable & Undetectable & Undetectable & \\
\hline
\end{tabular}

vaccination, and clinical manifestations of $\operatorname{PADs}^{4,5,7}$ in the absence of well-defined genetic markers ${ }^{32,33}$; in addition, an increased susceptibility to infections and autoimmunity or the existence of affected family members is required for the diagnosis of IgAdef per the ESID $^{5}$ (but not IUIS) criteria. Although the number of affected serum antibody isotypes provides a rough estimation of susceptibility to less (eg, IgAdef) versus more severe (CVID) disease complications in the short term in patients with PADs, ${ }^{4,5}$ it cannot accurately predict the longer-term outcome of individual patients within each PAD subgroup, particularly after immunoglobulin replacement therapy. In these settings B-cell maturation-associated defects identified by using flow cytometry have proved useful for the diagnosis and classification of patients with CVID $^{5,18,20}$ because they more precisely reflect the medium-term B cell-associated protective potential than their corresponding serum antibody isotype levels. However, some of the relationships observed in these studies between B-cell subset defects in blood and clinical manifestations of the disease ${ }^{14,15,18}$ have not been confirmed in other studies. ${ }^{16}$ Moreover, patients are usually classified based on relative B-cell subset numbers, ${ }^{14,15,18}$ which might be modified by changes in the other subsets, ${ }^{20}$ and no reference values per age group are used, ${ }^{14,15,18}$ which might limit the applicability of these classifications in, for example, children. ${ }^{34}$ In addition, such B-cell defects have been poorly explored in patients with IgG/Adef and those with IgAdef, ${ }^{19,35}$ whereas the blood distribution of B cells and PCs expressing distinct immunoglobulin subclasses has not been investigated thus far in either patients with CVID or those with IgAdef.

Here, for the first time, we investigated the distribution of $\mathrm{MBC}$ and $\mathrm{PC}$ subsets that express distinct immunoglobulin isotypes and IgH subclasses in the blood of patients with PADs and correlated the altered immune profiles identified with the diagnostic subgroups and clinical manifestations of the disease. Because the blood B-cell compartment is highly dynamic across a patient's lifetime, ${ }^{24,36-39}$ B-cell defects were defined per age group.

Overall, every patient with CVID, IgG/Adef, or IgAdef studied here showed decreased counts for 1 or more B-cell subsets. This contrasts with previous flow cytometric studies that detected Bcell defects in only $6 \%$ to $86 \%$ of patients with PADs, namely $77 \%$ to $86 \%$ in patients with CVID, ${ }^{14,15,18,20,23,40,41} 6 \%$ to $25 \%$ in patients with IgAdef, ${ }^{19,35}$ and $30 \%$ in patients with selective $\mathrm{IgG}$ subclass deficiency (with or without IgAdef). ${ }^{41}$ This high 
A

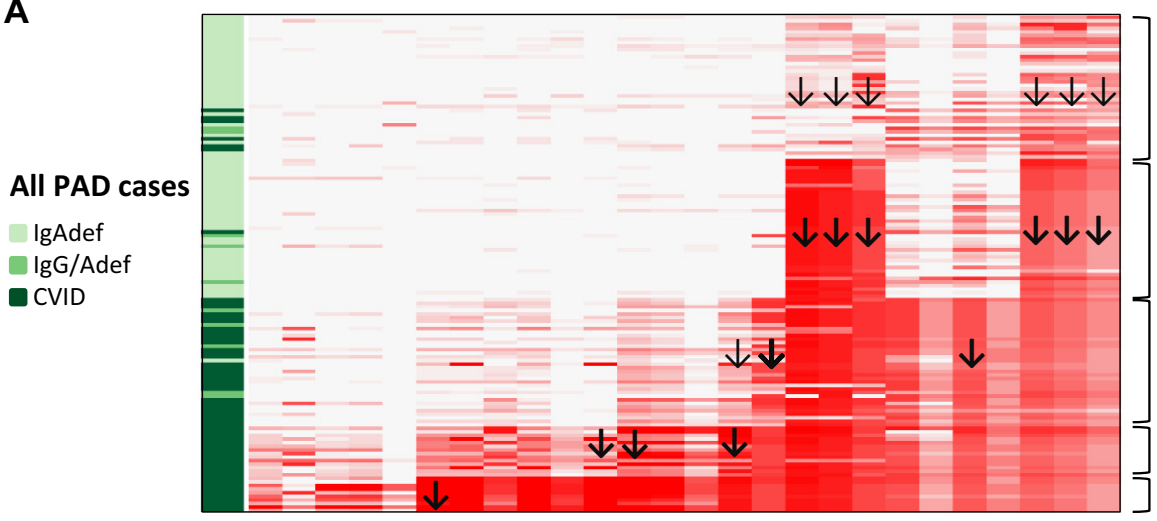

B

Selective IgA deficiency

ESID -

ESID +

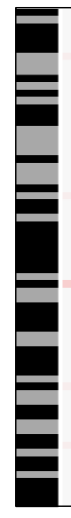

C

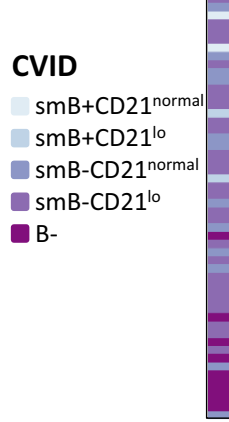

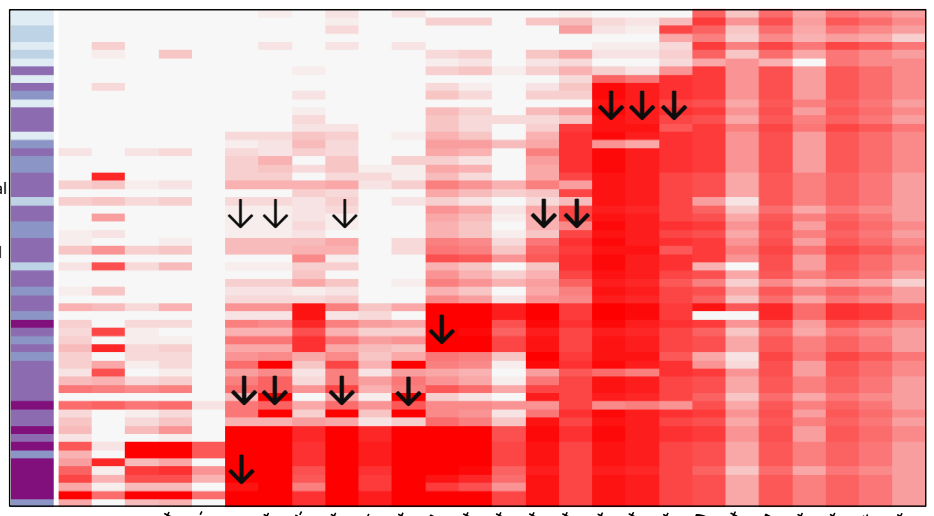
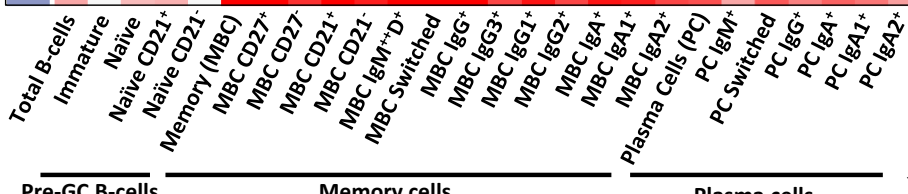

Memory cells

\section{is}

Plasma cells

\section{Clusters}

\section{PAD-1}

(Reduced smlgA1 ${ }^{+} /$smlgA2 $2^{+} \mathrm{MBCs}$ or $\mathrm{PCs}$ )

\section{PAD-2}

(Absent smlgA $A^{+} \mathrm{MBCs}$ )

PAD-3

( $\downarrow$ switched PCs, smlgA $A^{+}$and smlgG2 $2^{+} \mathrm{MBCs}$ )

PAD-4 ( $\left.\downarrow s \mathrm{smlgG} 1^{+} \mathrm{MBCs}\right)$

PAD-5 (Absent MBCs)

\section{Clusters}

\section{IgAdef-1}

(Reduced smlgA1 $1^{+}$smlgA2 $2^{+} \mathrm{MBCs}$ or $\mathrm{PCs}$ )

\section{IgAdef-2}

(Absent smlgA $\mathrm{A}^{+} \mathrm{MBCs}$ )

\section{Clusters}

CVID-1

(Reduced PCs)

CVID-2

(Absent smlgA1 $1^{+} \mathrm{MBCs}$ )

\section{CVID-3}

(Reduced smlgG2 ${ }^{+} \mathrm{MBCs}$ )

\section{CVID-4}

(Absent switched MBCs)

CVID-5

$=\left(\downarrow C D 27^{+} \mathrm{MBCS}\right)$

CVID-6

(Absent MBCs)

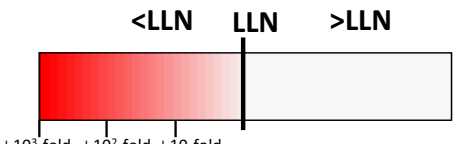

FIG 3. Clustering analysis-based heat map representing all patients with PADs (A) and those with IgAdef (B) and CVID (C) grouped according to their (altered) blood MBC and PC subset immune profiles. Each heat map represents absolute counts of the different B-cell subsets normalized by the LLN in HDs for the corresponding age group (columns) versus individual cases (rows). Higher red color intensities represent a deeper degree of deficiency in a $\log _{10}$ scale compared with the corresponding age-matched LLN. Individual patients (rows) are identified by (1) their IUIS (clinical) diagnosis (Fig 3, $A$; light green for patients with IgAdef, intermediate green for patients with IgG/Adef, and dark green for patients with CVID); (2) their corresponding ESID IgAdef diagnosis (Fig 3,B), including IgAdef cases that fulfilled (black) or not (gray) the ESID criteria for IgAdef; and (3) CVID EUROclass classification subgroup (Fig 3,C), smB ${ }^{+} \mathrm{CD} 21^{\text {normal }}, \operatorname{smB}^{+} \mathrm{CD} 21^{\text {lo }}$, $\mathrm{smB}^{-} \mathrm{CD} 21^{\text {normal }}, \mathrm{smB}^{-} \mathrm{CD} 21^{\mathrm{lo}}$, and $\mathrm{B}-$ cells from lighter to darker violet. The here-defined PAD-1 to PAD5 (Fig 3, A), IgAdef-1 and IgAdef-2 (Fig 3, B), and CVID-1 to CVID-6 (Fig 3,C) clusters identified by using the K-means algorithm, as well as the main characteristics of these groups, are depicted at the right side of each heat map. Black arrows indicate those MBC and PC subsets that contributed most to the specific identification of each patient cluster. 


\section{A Healthy donor}

\author{
Memory B-cells
}

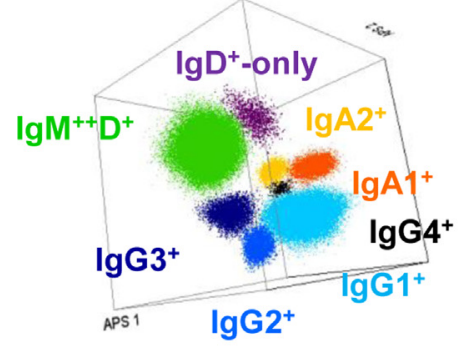

Plasma cells

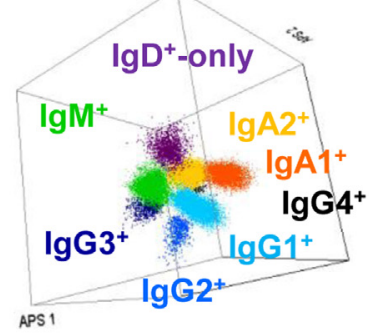

\section{CVID}
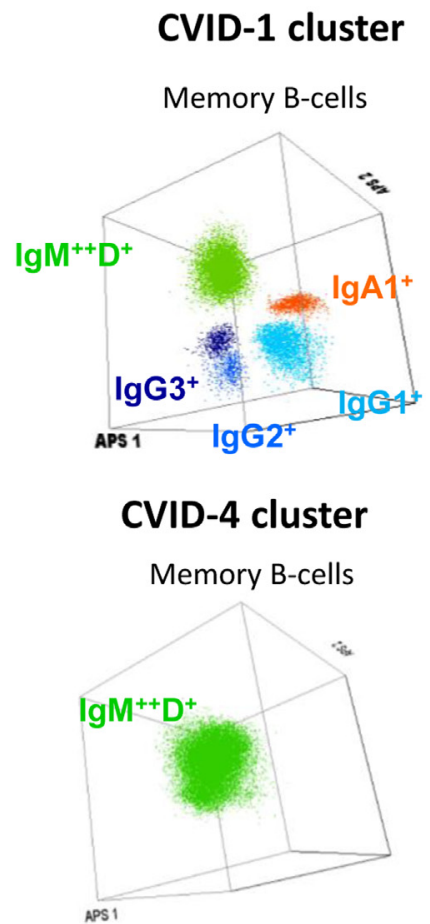

\section{B Selective IgA deficiency}

\section{IgAdef-1 cluster}

Memory B-cells

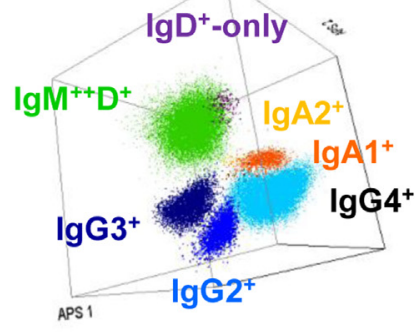

Plasma cells

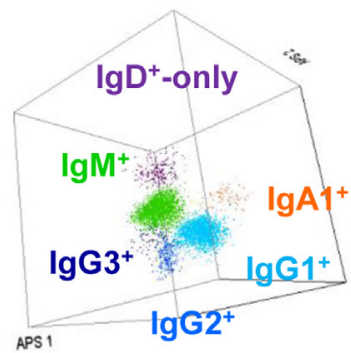

IgAdef-2 cluster

Memory B-cells

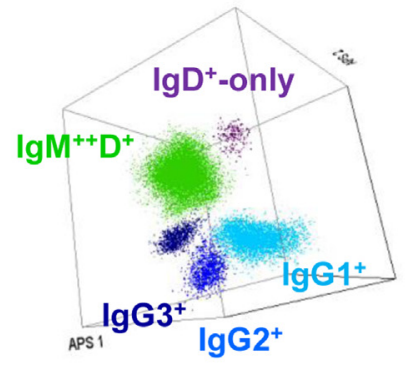

Plasma cells

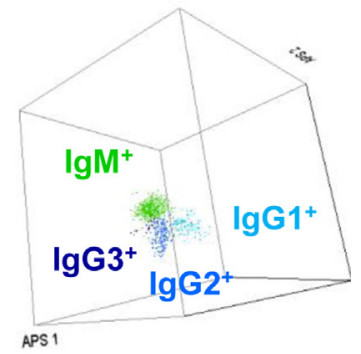

CVID-3 cluster

CVID-2 cluster

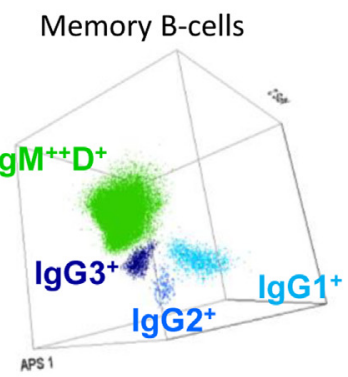

CVID-5 cluster

Memory B-cells

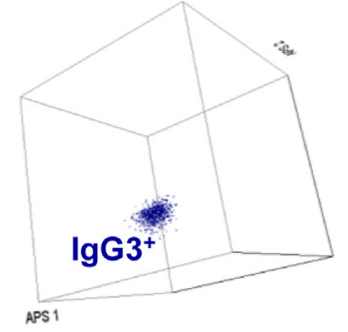

Memory B-cells

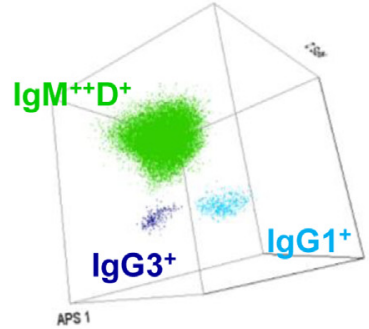

CVID-6 cluster

Memory B-cells

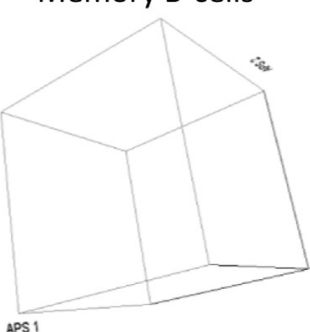

FIG 4. Illustrating dot plot examples of the numeric distribution of blood unswitched and switched MBC and $P C$ subsets expressing different immunoglobulin isotypes and subclasses in a representative HD (A) and in representative patients with IgAdef (B) and CVID (C). Each plot corresponds to 3-dimensional Automated Population Separator (APS) views of principal component 1 (PC1) versus PC2 versus PC3 of the distinct subsets of MBCs and PCs defined by the immunoglobulin isotype and subclass expressed: $\lg M\left(D^{+}\right)$in green, $\lg _{1}$ in light blue, $\lg _{2}$ in intermediate blue, $\lg _{3}$ in dark blue, $\lg _{4}$ in black, $\lg A_{1}$ in orange, $\lg A_{2}$ in yellow, and $\lg \mathrm{D}$ in violet. Additional cases from each group of patients with PADs are displayed in Figs E5 and E6. 
A

\section{Selective IgA deficiency}

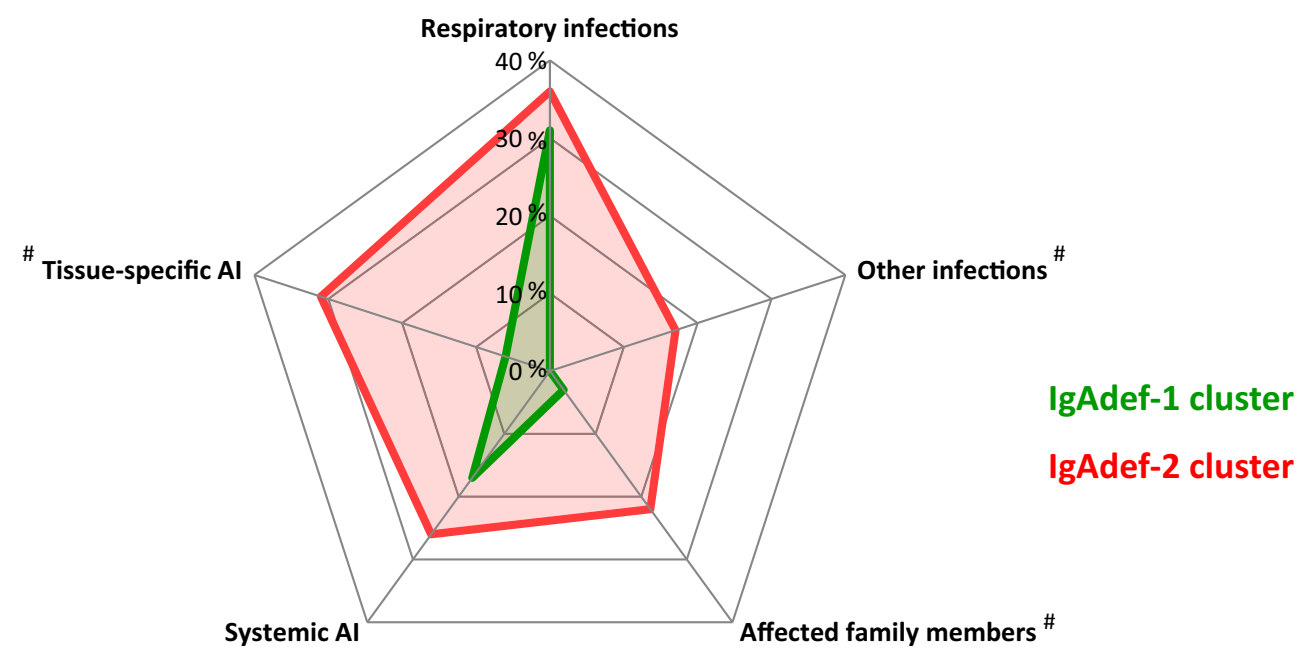

B CVID

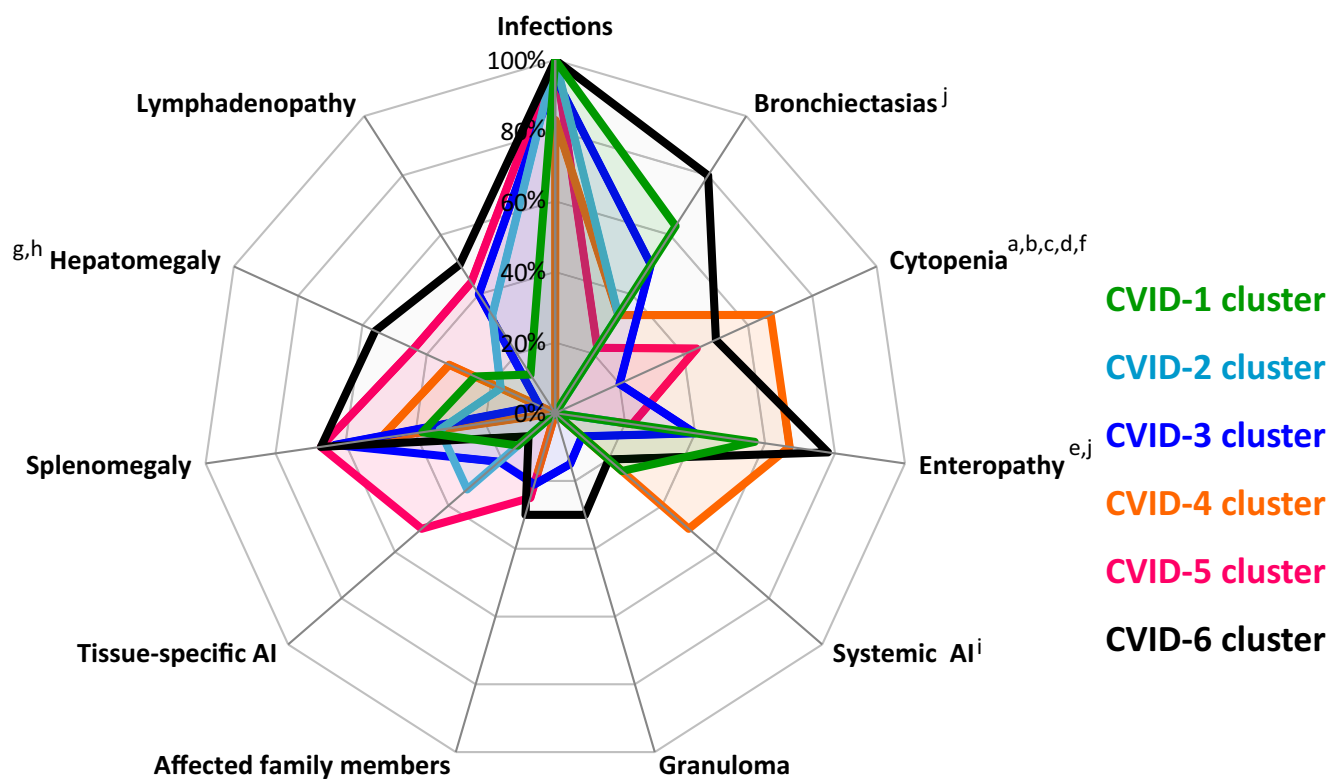

FIG 5. Frequency of distinct clinical manifestations of PADs and the existence (vs absence) of affected family members among the distinct clusters (ie, groups) of patients with IgAdef and those with CVID defined by their distinct patterns of altered blood B-cell and PC subset counts. Radar charts represent the percentage of patients with IgAdef (A) and patients with CVID (B) presenting with each type of clinical manifestation of the disease and the presence of family members affected by PADs. Colored lines indicate the distinct patient groups as defined by clustering analysis based on the B-cell and PC subset defects identified (see also Fig 3). $\# P \leq .05$ for patients with IgAdef-1 versus IgAdef-2. ${ }^{\mathrm{a}} P \leq .05$ for CVID-1 versus CVID-4. ${ }^{\mathrm{b}} P \leq .05$ for CVID-1 versus CVID-5. ${ }^{\mathrm{c}} P \leq .05$ for CVID-1 versus CVID-6. ${ }^{\mathrm{d}} P \leq .05$ for CVID-2 versus CVID-4. ${ }^{\mathrm{e}} P \leq .05$ for CVID-2 versus CVID-6. ${ }^{\mathrm{f}} P \leq .05$ for CVID-3 versus CVID-4. ${ }^{\mathrm{g}} P \leq .05$ for CVID-3 versus CVID-5. ${ }^{\mathrm{h}} P \leq .05$ for CVID-3 versus CVID-6. ${ }^{\mathrm{i}} P \leq .05$ for CVID-4 versus CVID-5. ${ }^{\mathrm{j}} P \leq .05$ for CVID-5 versus CVID-6. Al, Autoimmunity.

frequency of B-cell defects most likely reflects the more detailed dissection of the blood B-cell and PC compartments together with the greater sensitivity of our method versus previous methods, use of age-matched reference ranges, or both. However, despite the high sensitivity of the flow cytometric approach used here (similar to that of minimal residual disease detection by using nextgeneration flow ${ }^{25,42}$ ), several minor B-cell subsets, particularly within the $\mathrm{smIgG}^{+} \mathrm{PC}$ compartment (ie, $\mathrm{smIgG}_{1}{ }^{+}$to $\mathrm{smIgG}_{4}{ }^{+}$ 
PCs), were undetectable $(<0.01$ cells $/ \mu \mathrm{L})$ in 1 or more HDs from 2 or more age groups, limiting their potential diagnostic utility. Consequently, these subsets were not considered in the present study. Acquisition of greater numbers of cells with a greater sensitivity will become feasible soon with the new generation of highspeed cytometers and might overcome this limitation.

Recently produced short-lived blood $\mathrm{PCs},{ }^{43}$ particularly $\operatorname{IgA}^{+}$ PCs, emerged as the most sensitive population for diagnosis of PADs, followed by switched and nonswitched MBCs, with progressively more severe immunologic defects in the spectrum of IgAdef to IgG/Adef and CVID. Thus decreased $\operatorname{smIgA}_{1}{ }^{+}$and/ or $\operatorname{smIgA}_{2}{ }^{+} \mathrm{PC}$ counts were found in all patients with PADs, except in 2 patients with IgAdef, who showed reduced $\operatorname{smIgA}{ }_{1}{ }^{+}$ and $\mathrm{smIg} \mathrm{A}_{2}^{+} \mathrm{MBC}$ counts. In addition, decreased total and/or switched PC counts emerged as a hallmark of CVID, which is in line with previous bone marrow and lymph node findings. ${ }^{44,45}$ Of note, patients with IgAdef showed cellular defects typically restricted to $\mathrm{smIgA}^{+} \mathrm{PCs}$ and $\mathrm{MBCs}$, despite $\mathrm{IgG}^{+} \mathrm{MBC}$ and PC counts also being decreased in $15 \%$ and $29 \%$ of patients with IgAdef versus $30 \%$ and $90 \%$ patients with IgG/Adef and $90 \%$ and $98 \%$ patients with CVID. Nevertheless, compared with a previous study ${ }^{22}$ in which less than $10 \%$ of patients with IgAdef had smIgA ${ }^{+}$MBCs, a greater percentage of our patients with IgAdef showed circulating $\operatorname{smIgA}^{+}$MBCs (50\%), PCs (approximately 40\%), or both. This discrepancy is probably caused by the greater sensitivity of our EuroFlow strategy and method with $5 \times 10^{6}$ or more (vs $5 \times 10^{4}$ ) cells analyzed. ${ }^{22}$

Our findings are in line with those of previous studies demonstrating $S \alpha$-switch recombination in blood B cells from 2 of 4 patients with IgAdef. ${ }^{46}$ Interestingly, patients with IgAdef who showed a preserved IgA-switching capacity (IgAdef- 1 cases) displayed a milder clinical phenotype, with less risk factors for CVID progression (eg, autoimmunity ${ }^{47}$ but a similar prevalence of recurrent respiratory tract infections. In addition, they were younger (both at presentation and at time of analysis) than IgAdef- 2 cases, which could potentially reflect progressive accumulation of more severe defects in blood $\mathrm{IgA}^{+} \mathrm{MBCs}$ and PCs in parallel to a greater frequency and severity of clinical manifestations. However, all cases categorized as IgAdef- 1 that have been re-evaluated (11/32) after a median follow-up of 25 months (range, 10-52 months) continue to show preserved IgAswitching capacity (data not shown), and none of the 26 IgAdef- 2 cases followed since their inclusion in this study have evolved to CVID (median follow-up, 2 years; data not shown). Nonetheless, longer follow-up times are needed to rule out an effect of age at diagnosis on the altered blood B-cell immune profile and clinical manifestations of patients with IgAdef. Altogether, these findings suggest that detailed evaluation of blood B-cell and PC defects might contribute to an improved classification and clinical management of IgAdef patients.

Complete lack of blood switched PCs was the hallmark of CVID. Although reduced switched MBC counts have been extensively reported in patients with CVID ${ }^{14-16,18,20}$ this is the first time that these cells were dissected at the immunoglobulin subclass level, similar to what is routinely done for serum $\mathrm{IgG}_{1 \text { - }}$ 4 levels. Progressive deterioration in IgG-switching capacity was observed in MBCs of patients with CVID, which directly correlated with their consecutive location in the IGHC gene locus: $\operatorname{IgM}<\operatorname{IgG}_{3}<\operatorname{IgG}_{1}<\operatorname{IgG}_{2}$. In line with these results, Piqueras et $\mathrm{al}^{14}$ showed a similar pattern of reduced mRNA expression for the different immunoglobulin isotypes/immunoglobulin subclasses: $\operatorname{IgM}>\operatorname{IgG}_{3} \geq \operatorname{IgG}_{1}>\operatorname{IgG}_{2}>\operatorname{IgA}_{1}>\operatorname{IgA}_{2}>\operatorname{IgG}_{4}$. At present, it is well established that downstream IgG subclasses are produced, at least in part, by consecutive switching of B-cells during repeated rounds of MBC response, ${ }^{48-51}$ leading to a greater frequency of somatic hypermutation ${ }^{48,50,51}$ and switch regions bearing remnants of indirect class-switching ${ }^{50}$ in cells expressing downstream immunoglobulin isotypes/immunoglobulin subclasses. Interestingly, we recently identified a similar pattern of sequential production of MBC expressing distinct immunoglobulin subclasses during a lifetime. ${ }^{24}$

These findings, together with recent observations using genome-wide sequencing approaches, suggest that consecutive switching along the $I G H C$ locus might deteriorate in patients with PADs, possibly because of combined hypomorphic/deleterious variants, ${ }^{52-54}$ haploinsufficient genes, ${ }^{55-58}$ and epigenetic modifications $^{59}$ involving B-cell response pathways rather than a single genetic defect. Progressive deterioration of sequential classswitching along the $I G H C$ locus, along with reduced MBCs and lack of PCs, leads to a progressively more restricted repertoire and decreased functional capacity of MBCs expressing downstream IgG subclasses. Of note, previous flow cytometric approaches typically excluded patients with CVID with less than $1 \% \mathrm{~B}$ cells from further analyses (and subclassification) caused by insufficient B-cell numbers for robust dissection of its major subsets. ${ }^{15,18}$ However, here we were able to identify B cells also in all patients with CVIDs presenting less than $1 \% \mathrm{~B}$ cells, including circulating blood naive B cells in 8 of 9 cases and $\mathrm{MBCs}$ in 4 of 9 cases; this is in contrast to BTK-deficient patients evaluated with this same highly sensitive approach, who systematically showed undetectable peripheral blood B cells (data not shown).

Among different approaches used to categorize CVID, the EUROclass classification (see Table E11) is the most widely used because of its clinical utility. This classification allows us to relate alterations in the distribution of peripheral blood B-cell subsets with the presence of clinical manifestations, such as a decrease in $\mathrm{MBC}$ counts ( $\mathrm{smB}^{-}$group) and the occurrence of splenomegaly, as also confirmed here (see Table E13 in this article's Online Repository at www.jacionline.org). In this regard our proposed stratification criteria for CVID into CVID-1 to CVID-6 clusters based on MBC immunoglobulin isotype and IgH-subclass subset immune profile in blood also showed association with other disease features (eg, autoimmune cytopenias and hepatomegaly) that have been related to a lower survival in patients with CVID $^{10}$ but that did not correlate with the EUROclass classification either in the present or other larger previously reported CVID patient series. ${ }^{18}$ In addition, the highly sensitive approach used here allowed detection of low blood $\mathrm{MBC}$ and $\mathrm{PC}$ counts expressing $\mathrm{IgG}_{1}$ to $\mathrm{IgG}_{4}$ and $\mathrm{IgA}_{1}$ to $\operatorname{IgA}_{2}$ subclasses, demonstrating that most patients with CVID retain the ability for class-switching, including the great majority $(>70 \%)$ of $\mathrm{smB}^{-}$cases presenting with dramatically reduced numbers of switched MBCs. ${ }^{18}$ This is consistent with more laborious functional studies that demonstrated the (residual) capacity of B cells to produce IgG, also among $\mathrm{smB}^{-}$patients. $^{21}$ In fact, our EuroFlow strategy for highly sensitive immunoglobulin subclass analysis of blood B cells and PCs identified 6 CVID subgroups with different IgG-switching patterns and clinical profiles, even within $\mathrm{smB}^{-}$patients with CVIDs. The 3 clinically milder subgroups included patients capable of producing MBCs of the (first 3) $\mathrm{IgM} / \mathrm{IgD}, \mathrm{IgG}_{3}$, and $\mathrm{IgG}_{1}$ immunoglobulin isotypes/subclasses located upstream in 
the $I G H C$ locus (independently of $\mathrm{smIgG}_{2}{ }^{+}$and $\mathrm{IgA}^{+} \mathrm{MBC}$ counts), who might require less $\mathrm{IgG}$ substitution therapy. ${ }^{21}$ In fact, despite patients of all groups having a greater frequency of infection, those within the CVID-1 to CVID-3 groups required less hospital care (data not shown). CVID-4 cases were still capable of $\mathrm{CD} 27^{+}$unswitched MBC production and typically presented with cytopenias, such as in patients with hyper-IgM syndromes. $^{60-62}$ However, they had no PCs (including no $\operatorname{IgM}^{+}$ PCs in all but 1 case), and they showed a typical CVID-related serum antibody profile in the absence of in vitro functional defects associated with hyper-IgM syndromes (data not shown). ${ }^{63}$ Interestingly, 3 of 4 patients with rheumatoid arthritis (an immune complex-mediated autoimmune disease ${ }^{64}$ ) in our series clustered together in the CVID-4 cluster (data not shown), which only has preserved $\operatorname{IgM}^{++} \operatorname{IgD}^{+}$MBCs.

The 2 clinically more severe CVID-5 and (particularly) CVID6 patient subgroups had dramatically decreased $\mathrm{CD}_{2} 7^{+}$unswitched and switched MBC counts, except for $\mathrm{CD} 27^{-} \mathrm{CD} 21^{-} \mathrm{IgG}_{3}{ }^{+} \mathrm{MBC}$ counts, which were found to be almost normal in CVID-5 (but not CVID-6) cases. From the clinical point of view, CVID-5 and CVID- 6 cases specifically showed disease symptoms (eg, organomegalies) reflecting an impaired ability to mount germinal center (GC) responses. ${ }^{24,50,65}$ Altogether, these findings suggest that even if the residual $\mathrm{CD} 27^{-} \mathrm{CD} 21^{-} \mathrm{smIgG}_{3}{ }^{+} \mathrm{MBC}$ could offer some immune protection in CVID-5 cases, in CVID-5 and CVID-6 cases the underlying immune dysregulation leads to a polyclonal lymphocytic infiltration of secondary lymphoid tissues previously associated with increased risk for lymphoid malignancy in patients with CVID. ${ }^{66}$ In fact, all patients with hematologic tumors were clustered as CVID-5 and CVID-6 cases (see Table E12). Although it is tempting to hypothesize that such stepwise deterioration of IgGswitching capacity might reflect disease progression, no significant differences in age (or time from diagnosis) were observed among the above CVID patient subgroups (except for CVID-6 cases who were older at the time of analysis than CVID-2 cases and the time from diagnosis, which was greater in CVID-6 vs CVID-2 and CVID-3 cases, data not shown).

The most severe CVID immunologic phenotype, CVID-6, also showed significantly reduced pre-GC B-cell counts, reflecting a markedly defective bone marrow B-cell production. ${ }^{18,20,45}$ Most blood B cells in these patients showed an immature/transitional phenotype, reflecting their premature egress from bone marrow, ${ }^{43}$ whereas residual naive $B$ cells were enriched in the minor CD2 $1^{\text {lo }}$ naive B-cell subset. Reduced pre-GC B-cell counts, together with the low in vitro response of both immature and $\mathrm{CD} 21^{\text {lo }}$ naive $\mathrm{B}$ cells, ${ }^{43,67}$ might explain the marked antigen-experienced B-cell defect involving all immunoglobulin isotypes found in CVID-6 cases. In line with previous observations, ${ }^{20}$ these patients also had decreased naive $\mathrm{T} \mathrm{CD}^{+}$and $\mathrm{T} \mathrm{CD} 8^{+}$counts versus agematched HDs and other patients with CVID (data not shown), but they did not fulfill the diagnostic criteria for late-onset combined immunodeficiency. ${ }^{5}$ The potential existence of underlying hypomorphic defects and variants of genes related to the production of lymphocytes (RAG, DCLRE1C, and NHEJ1) previously related to $C V I D-l i k e$ clinical phenotypes remains to be more deeply investigated in these CVID-6 cases. ${ }^{52-54}$

In summary, detailed dissection of circulating MBCs and PCs in patients with PADs into subsets expressing distinct immunoglobulin subclasses provides complementary information to serum antibody isotype levels and might contribute to a better understanding of the pathogenesis of PADs and an improved diagnosis, subclassification, and monitoring (particularly in case of immunoglobulin replacement therapy) of the disease. Blood PCs emerged here as the most sensitive diagnostic blood cellular compartment, whereas analysis of blood MBC subsets appeared informative to discriminate patients with different clinical profiles. However, further multicentric studies in large age-matched case-control cohorts are needed to replicate and validate the clinical utility and feasibility of our proposed approach for detailed and sensitive dissection of blood B-cell and PC subsets for the diagnosis and classification of PADs. At the same time, use of EuroFlow databases and tools for automated gating and reporting of flow cytometric data will facilitate its implementation in routine diagnostics. ${ }^{68,69}$

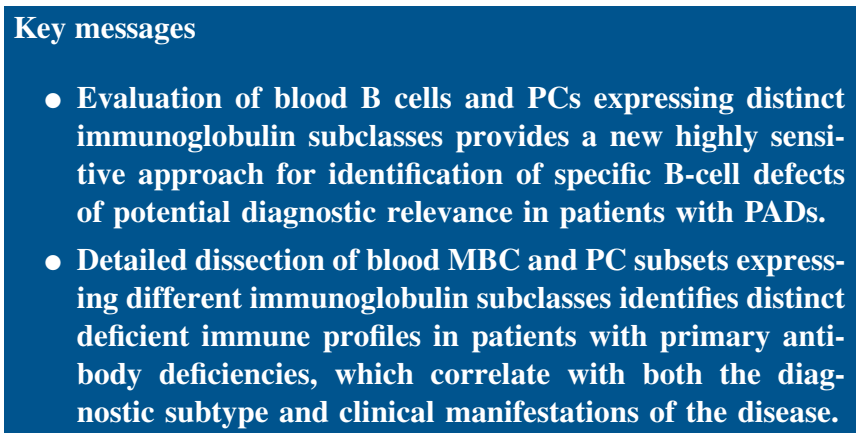

\section{REFERENCES}

1. Durandy A, Kracker S, Fischer A. Primary antibody deficiencies. Nat Rev Immunol 2013;13:519-33.

2. Wood PM. Primary antibody deficiency syndromes. Curr Opin Hematol 2010;17: 356-61.

3. Wang N, Hammarstrom L. IgA deficiency: what is new? Curr Opin Allergy Clin Immunol 2012;12:602-8.

4. Picard C, Bobby Gaspar H, Al-Herz W, Bousfiha A, Casanova J-L, Chatila T, et al. International Union of Immunological Societies: 2017 Primary Immunodeficiency Diseases Committee Report on Inborn Errors of Immunity. J Clin Immunol 2018; 38:96-128.

5. Abinun M, Albert M, Buckland S.B.C.M, Bustamante J, Cant A, Casanova J.-L, et al., ESID registry-working definitions for clinical diagnosis of PID; European Society for Immunodeficiencies. Available at: https://esid.org/Working-Parties/ Registry-Working-Party/Diagnosis-criteria. Accessed January 10, 2019.

6. Ballow M. Primary immunodeficiency disorders: antibody deficiency. J Allergy Clin Immunol 2002;109:581-91.

7. Jolles $\mathrm{S}$. The variable in common variable immunodeficiency: a disease of complex phenotypes. J Allergy Clin Immunol Pract 2013;1:545-56.

8. Yazdani R, Azizi G, Abolhassani H, Aghamohammadi A. Selective IgA deficiency: epidemiology, pathogenesis, clinical phenotype, diagnosis, prognosis and management. Scand J Immunol 2017;85:3-12.

9. Cunningham-Rundles C. The many faces of common variable immunodeficiency. Hematology Am Soc Hematol Educ Progr 2012;2012:301-5.

10. Chapel H, Lucas M, Patel S, Lee M, Cunningham-Rundles C, Resnick E, et al. Confirmation and improvement of criteria for clinical phenotyping in common variable immunodeficiency disorders in replicate cohorts. J Allergy Clin Immunol 2012;130:1197-8.

11. Chapel H. Common variable immunodeficiency disorders (CVID)—diagnoses of exclusion, especially combined immune defects. J Allergy Clin Immunol Pract 2016;4:1158-9.

12. Bertinchamp R, Gérard L, Boutboul D, Malphettes M, Fieschi C, Oksenhendler E, et al. Exclusion of patients with a severe T-cell defect improves the definition of common variable immunodeficiency. J Allergy Clin Immunol Pract 2016;4: $1147-57$.

13. Bonilla FA, Barlan I, Chapel H, Costa-Carvalho BT, Cunningham-Rundles C, de la Morena MT, et al. International consensus document (ICON): common variable immunodeficiency disorders. J Allergy Clin Immunol Pract 2016;4:38-59. 
14. Piqueras B, Lavenu-Bombled C, Galicier L, Bergeron-van der Cruyssen F, Mouthon L, Chevret S, et al. Common variable immunodeficiency patient classification based on impaired B cell memory differentiation correlates with clinical aspects. J Clin Immunol 2003;23:385-400.

15. Warnatz K, Denz A, Drager R, Braun M, Groth C, Wolff-Vorbeck G, et al. Severe deficiency of switched memory B cells $(\mathrm{CD} 27(+) \operatorname{IgM}(-) \operatorname{IgD}(-))$ in subgroups of patients with common variable immunodeficiency: a new approach to classify a heterogeneous disease. Blood 2002;99:1544-51.

16. Al Kindi M, Mundy J, Sullivan T, Smith W, Kette F, Smith A, et al. Utility of peripheral blood B cell subsets analysis in common variable immunodeficiency. Clin Exp Immunol 2012;167:275-81.

17. Piatosa B, Pac M, Siewiera K, Pietrucha B, Klaudel-Dreszler M, HeropolitańskaPliszka E, et al. Common variable immune deficiency in children-clinical characteristics varies depending on defect in peripheral B cell maturation. J Clin Immunol 2013:33:731-41.

18. Wehr C, Kivioja T, Schmitt C, Ferry B, Witte T, Eren E, et al. The EUROclass trial: defining subgroups in common variable immunodeficiency. Blood 2008;111:77-85.

19. Aghamohammadi A, Abolhassani H, Biglari M, Abolmaali S, Moazzami K, Tabatabaeiyan M, et al. Analysis of switched memory B cells in patients with IgA deficiency. Int Arch Allergy Immunol 2011;156:462-8.

20. Driessen GJ, van Zelm MC, van Hagen PM, Hartwig NG, Trip M, Warris A, et al B-cell replication history and somatic hypermutation status identify distinct pathophysiologic backgrounds in common variable immunodeficiency. Blood 2011; 118:6814-23.

21. Rösel AL, Scheibenbogen C, Schliesser U, Sollwedel A, Hoffmeister B, Hanitsch L, et al. Classification of common variable immunodeficiencies using flow cytometry and a memory B-cell functionality assay. J Allergy Clin Immunol 2015;135:198-208.

22. Marasco E, Farroni C, Cascioli S, Marcellini V, Scarsella M, Giorda E, et al. Bcell activation with $\mathrm{CD} 40 \mathrm{~L}$ or $\mathrm{CpG}$ measures the function of B-cell subsets and identifies specific defects in immunodeficient patients. Eur J Immunol 2017;47: 131-43.

23. Driessen GJ, Dalm VASH, van Hagen PM, Grashoff HA, Hartwig NG, van Rossum $\mathrm{AMC}$, et al. Common variable immunodeficiency and idiopathic primary hypogammaglobulinemia: two different conditions within the same disease spectrum. Haematologica 2013;98:1617-23.

24. Blanco E, Pérez-Andrés M, Arriba-Méndez S, Contreras-Sanfeliciano T, Criado I, Pelak O, et al. Age-associated distribution of normal B-cell and plasma cell subsets in peripheral blood. J Allergy Clin Immunol 2018;141:2208-19.

25. Flores-Montero J, Sanoja-Flores L, Paiva B, Puig N, García-Sánchez O, Böttcher S, et al. Next Generation Flow for highly sensitive and standardized detection of minimal residual disease in multiple myeloma. Leukemia 2017; 31:2094-103.

26. Blanco E, Perez-Andres M, Sanoja-Flores L, Wentink M, Pelak O, Martín-Ayuso $\mathrm{M}$, et al. Selection and validation of antibody clones against IgG and IgA subclasses in switched memory B-cells and plasma cells. J Immunol Methods 2017 [Epub ahead of print].

27. Kalina T, Flores-Montero J, van der Velden VHJ, Martin-Ayuso M, Böttcher S, Ritgen $\mathrm{M}$, et al. EuroFlow standardization of flow cytometer instrument settings and immunophenotyping protocols. Leukemia 2012;26:1986-2010.

28. Rudolf-Oliveira RCM, Goncalves KT, Martignago ML, Mengatto V, Gaspar PC, de Moraes ACR, et al. Determination of lymphocyte subset reference ranges in peripheral blood of healthy adults by a dual-platform flow cytometry method. Immunol Lett 2015;163:96-101.

29. R Core Team. R: a language and environment for statistical computing. Vienna (Austria): R Foundation; 2015.

30. MacQueen J. Some methods for classification and analysis of multivariate observations. In: Proceedings of the Fifth Berkeley Symposium on Mathematical Statistics and Probability, Volume 1: Statistics. Berkeley (CA): University of California Press; 1967. pp. 281-97.

31. Warnes GR, Bolker B, Bonebakker L, Gentleman R, Liaw WHA, Lumley T, et al. gplots: various $\mathrm{R}$ programming tools for plotting Data. $\mathrm{R}$ Packag. version 2.17.0.2015.

32. Bogaert DJA, Dullaers M, Lambrecht BN, Vermaelen KY, De Baere E, Haerynck F. Genes associated with common variable immunodeficiency: one diagnosis to rule them all? J Med Genet 2016;53:575-90.

33. Kienzler A-K, Hargreaves CE, Patel SY. The role of genomics in common variable immunodeficiency disorders. Clin Exp Immunol 2017;188:326-32.

34. Schatorjé EJH, Gemen EFA, Driessen GJA, Leuvenink J, van Hout RWNM, van der Burg M, et al. Age-matched reference values for B-lymphocyte subpopulations and CVID classifications in children. Scand J Immunol 2011;74:502-10.

35. Nechvatalova J, Pikulova Z, Stikarovska D, Pesak S, Vlkova M, Litzman J. Blymphocyte subpopulations in patients with selective IgA deficiency. J Clin Immunol 2012:32:441-8.
36. Piątosa B, Wolska-Kuśnierz B, Pac M, Siewiera K, Gałkowska E, Bernatowska E. B cell subsets in healthy children: reference values for evaluation of B cell maturation process in peripheral blood. Cytometry B Clin Cytom 2010;78:372-81.

37. van Gent R, van Tilburg CM, Nibbelke EE, Otto SA, Gaiser JF, Janssens-Korpela $\mathrm{PL}$, et al. Refined characterization and reference values of the pediatric T- and Bcell compartments. Clin Immunol 2009;133:95-107.

38. Morbach H, Eichhorn EM, Liese JG, Girschick HJ. Reference values for B cell subpopulations from infancy to adulthood. Clin Exp Immunol 2010;162:271-9.

39. van den Heuvel D, Jansen MAE, Nasserinejad K, Dik WA, van Lochem EG, BakkerJonges LE, et al. Effects of nongenetic factors on immune cell dynamics in early childhood: the Generation R Study. J Allergy Clin Immunol 2017;139:1923-34.e17.

40. Huck K, Feyen O, Ghosh S, Beltz K, Bellert S, Niehues T. Memory B-cells in healthy and antibody-deficient children. Clin Immunol 2009;131:50-9.

41. Bogaert DJA, De Bruyne M, Debacker V, Depuydt P, De Preter K, Bonroy C, et al The immunophenotypic fingerprint of patients with primary antibody deficiencies is partially present in their asymptomatic first-degree relatives. Haematologica 2017; 102:192-202.

42. Theunissen P, Mejstrikova E, Sedek L, van der Sluijs-Gelling AJ, Gaipa G, Bartels M, et al. Standardized flow cytometry for highly sensitive MRD measurements in B-cell acute lymphoblastic leukemia. Blood 2017;129:347-57.

43. Perez-Andres M, Paiva B, Nieto WG, Caraux A, Schmitz A, Almeida J, et al. Human peripheral blood B-cell compartments: a crossroad in B-cell traffic. Cytometry B Clin Cytom 2010;78(suppl 1):S47-60.

44. Unger S, Seidl M, Schmitt-Graeff A, Bohm J, Schrenk K, Wehr C, et al. Ill-defined germinal centers and severely reduced plasma cells are histological hallmarks of lymphadenopathy in patients with common variable immunodeficiency. J Clin Immunol 2014;34:615-26.

45. Ochtrop MLG, Goldacker S, May AM, Rizzi M, Draeger R, Hauschke D, et al. T and $\mathrm{B}$ lymphocyte abnormalities in bone marrow biopsies of common variable immunodeficiency. Blood 2011;118:309-18.

46. Wang Z, Yunis D, Irigoyen M, Kitchens B, Bottaro A, Alt F. Discordance between IgA switching at the DNA level and IgA expression at the mRNA level in IgAdeficient patients. Clin Immunol 1999;91:263-70.

47. Aghamohammadi A, Mohammadi J, Parvaneh N, Rezaei N, Moin M, Espanol T, et al. Progression of selective IgA deficiency to common variable immunodeficiency. Int Arch Allergy Immunol 2008;147:87-92.

48. Jackson KJ, Wang Y, Collins AM. Human immunoglobulin classes and subclasses show variability in VDJ gene mutation levels. Immunol Cell Biol 2014:92:729-33.

49. Collins AM, Jackson KJL. A temporal model of human IgE and IgG antibody function. Front Immunol 2013;4:235.

50. Berkowska MA, Driessen GJA, Bikos V, Grosserichter-Wagener C, Stamatopoulos K, Cerutti A, et al. Human memory B cells originate from three distinct germinal center-dependent and -independent maturation pathways. Blood 2011;118:2150-8.

51. de Jong BG, IJspeert H, Marques L, van der Burg M, van Dongen JJ, Loos BG, et al. Human IgG2- and IgG4-expressing memory B cells display enhanced molecular and phenotypic signs of maturity and accumulate with age. Immunol Cell Biol 2017;95:744-52.

52. Volk T, Pannicke U, Reisli I, Bulashevska A, Ritter J, Bjorkman A, et al DCLRE1C (ARTEMIS) mutations causing phenotypes ranging from atypical severe combined immunodeficiency to mere antibody deficiency. Hum Mol Genet 2015;24:7361-72.

53. Abolhassani H, Cheraghi T, Rezaei N, Aghamohammadi A, Hammarstrom L. Common variable immunodeficiency or late-onset combined immunodeficiency: a new hypomorphic JAK3 patient and review of the literature. J Investig Allergol Clin Immunol 2015;25:218-20.

54. Abolhassani H, Wang N, Aghamohammadi A, Rezaei N, Lee YN, Frugoni F, et al A hypomorphic recombination-activating gene 1 (RAG1) mutation resulting in a phenotype resembling common variable immunodeficiency. J Allergy Clin Immunol 2014:134:1375-80.

55. Kuehn HS, Boisson B, Cunningham-Rundles C, Reichenbach J, Stray-Pedersen A, Gelfand EW, et al. Loss of B cells in patients with heterozygous mutations in IKAROS. N Engl J Med 2016;374:1032-43.

56. Schubert D, Bode C, Kenefeck R, Hou TZ, Wing JB, Kennedy A, et al. Autosomal dominant immune dysregulation syndrome in humans with CTLA4 mutations. Nat Med 2014:20:1410-6.

57. Fliegauf M, Bryant VL, Frede N, Slade C, Woon S-T, Lehnert K, et al. Haploinsufficiency of the NF-kappaB1 subunit p50 in common variable immunodeficiency. Am J Hum Genet 2015;97:389-403.

58. Tuijnenburg P, Lango Allen H, Burns SO, Greene D, Jansen MH, Staples E, et al. Loss-of-function nuclear factor $\mathrm{\kappa B}$ subunit 1 (NFKB1) variants are the most common monogenic cause of common variable immunodeficiency in Europeans. J Allergy Clin Immunol 2018;142:1285-96. 
59. Rodríguez-Cortez VC, del Pino-Molina L, Rodríguez-Ubreva J, Ciudad L, GómezCabrero D, Company C, et al. Monozygotic twins discordant for common variable immunodeficiency reveal impaired DNA demethylation during naïve-to-memory B-cell transition. Nat Commun 2015;6:7335.

60. Leven EA, Maffucci P, Ochs HD, Scholl PR, Buckley RH, Fuleihan RL, et al. Hyper IgM Syndrome: a Report from the USIDNET Registry. J Clin Immunol 2016; 36:490-501.

61. Qamar N, Fuleihan RL. The hyper IgM syndromes. Clin Rev Allergy Immunol 2014;46:120-30.

62. de la Morena MT. Clinical phenotypes of hyper-IgM syndromes. J Allergy Clin Immunol Pract 2016;4:1023-36.

63. O'Gorman MR, Zaas D, Paniagua M, Corrochano V, Scholl PR, Pachman LM Development of a rapid whole blood flow cytometry procedure for the diagnosis of X-linked hyper-IgM syndrome patients and carriers. Clin Immunol Immunopathol 1997;85:172-81.

64. Derksen VFAM, Huizinga TWJ, van der Woude D. The role of autoantibodies in the pathophysiology of rheumatoid arthritis. Semin Immunopathol 2017;39:437-46.
65. Fecteau JF, Côté G, Néron S. A new memory CD27-IgG + B cell population in peripheral blood expressing VH genes with low frequency of somatic mutation. J Immunol 2006;177:3728-36.

66. Chapel H, Lucas M, Lee M, Bjorkander J, Webster D, Grimbacher B, et al. Common variable immunodeficiency disorders: division into distinct clinical phenotypes. Blood 2008;112:277-86.

67. Isnardi I, Ng Y, Menard L, Meyers G, Saadoun D, Srdanovic I, et al. Complement receptor 2/CD21- human naive B cells contain mostly autoreactive unresponsive clones. Blood 2010;115:5026-36.

68. Lhermitte L, Mejstrikova E, van der Sluijs-Gelling AJ, Grigore GE, Sedek L, Bras AE, et al. Automated database-guided expert-supervised orientation for immunophenotypic diagnosis and classification of acute leukemia. Leukemia 2018;32: 874-81.

69. van der Burg M, Kalina T, Pérez-Andrés M, Vlokova M, López-Granados E, Blanco E, et al. The EuroFlow PID orientation tube for flow cytometric diagnostic screening of primary immunodeficiencies of the lymphoid system. Front Immunol 2019, eCollection. 